2013

\title{
Motivating the Unmotivated Child: Using Psychosocial Intervention Methods in the School
}

\author{
Kristi Fickes \\ University of North Dakota \\ Kelsey Hoffmann \\ University of North Dakota
}

How does access to this work benefit you? Let us know!

Follow this and additional works at: https://commons.und.edu/ot-grad

Part of the Occupational Therapy Commons

\section{Recommended Citation}

Fickes, Kristi and Hoffmann, Kelsey, "Motivating the Unmotivated Child: Using Psychosocial Intervention Methods in the School" (2013). Occupational Therapy Capstones. 214.

https://commons.und.edu/ot-grad/214

This Scholarly Project is brought to you for free and open access by the Department of Occupational Therapy at UND Scholarly Commons. It has been accepted for inclusion in Occupational Therapy Capstones by an authorized administrator of UND Scholarly Commons. For more information, please contact und.commons@library.und.edu. 
MOTIVATING THE UNMOTIVATED CHILD: USING PSYCHOSOCIAL INTERVENTION METHODS IN THE SCHOOL

\author{
by
}

Kristi Fickes, MOTS; Kelsey Hoffmann, MOTS

Advisor: Sarah K. Nielsen PhD, OTR/L

A Scholarly Project

Submitted to the Occupational Therapy Department

of the

University of North Dakota

In partial fulfillment of the requirements

for the degree of

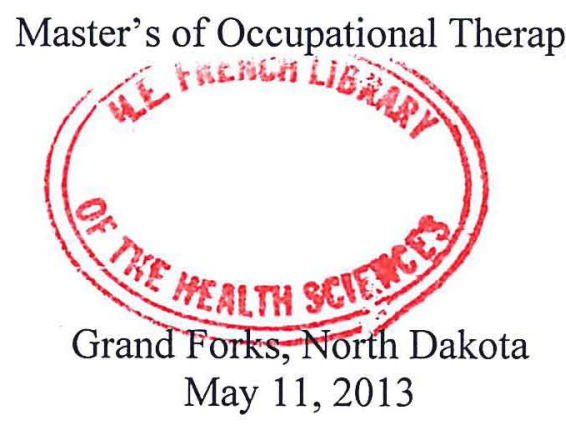




\section{APPROVAL PAGE}

This Scholarly Project Paper, submitted by Kristi Fickes and Kelsey Hoffmann in partial fulfillment of the requirement for the Degree of Masters of Occupational Therapy from the University of North Dakota, has been read by the Faculty Advisor under whom the work has ben done and is hereby approved.

Sah thish PKD, OTRK

Faculty Advisor

$$
4-19-13
$$

Date 


\section{PERMISSION}

Title: $\quad$ Article for submission: "Motivating the Unmotivated Child: Using Psychosocial Intervention Methods in the School"

Department: $\quad$ Occupational Therapy

Degree: $\quad$ Master's of Occupational Therapy

In presenting this Scholarly Project in partial fulfillment of the requirements for a graduate degree from the University of North Dakota, we agree that the Department of Occupational Therapy shall make it freely available for inspection. We further agree that permission for extensive copying for scholarly purposes may be granted by the professor who supervised our work or, in her absence, by the Chairperson of the Department. It is understood that any copying or publication or other use of this Scholarly Project of part of thereof for financial gain shall not be allowed without our written permission. It is also understood that due recognition shall be given to us and the University of North Dakota in any scholarly use which may be made of any material in our Scholarly Project Report.

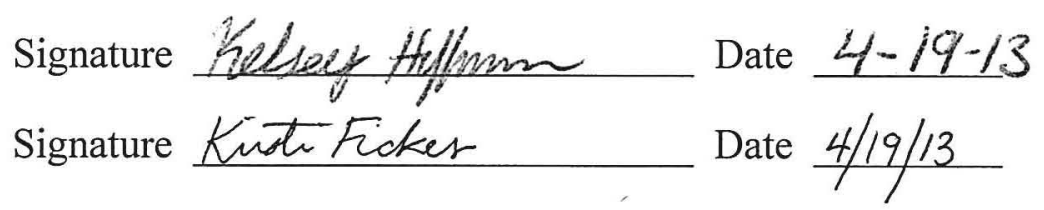




\section{TABLE OF CONTENTS}

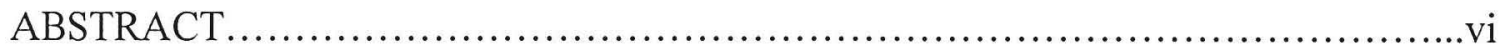

CHAPTER

I. INTRODUCTION..................................................

Key Concepts and Terminology ........................................

Organization of Project..................................................

II. LITERATURE REVIEW ..........................................

Occupational Therapy Defined......................................

History of Occupational Therapy..................................... 8

Psychosocial Issues in School-Aged Children.........................9

Why Psychosocial Issues Should be Addressed at School..............10

School-Based Occupational Therapy...............................11

Addressing Psychosocial Issues..................................12

Barriers to Using Psychosocial Intervention Methods.................13

Interventions.....................................................

Concepts......................................................... 15

Self-Determination........................................... 15

Self-Regulation...............................................

Cognitive Behavioral Theory ....................................17

Cognitive Techniques........................................20

Behavioral Techniques.......................................21

iv 


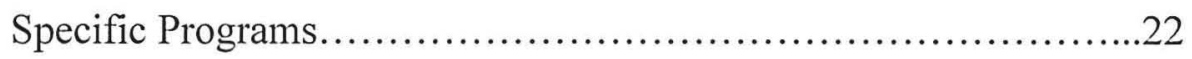

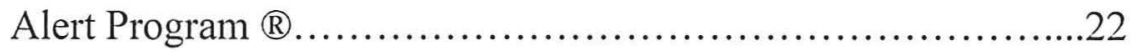

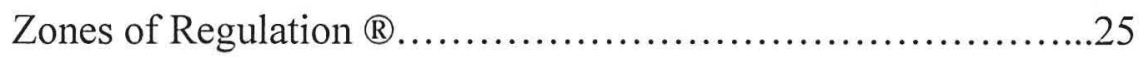

Think Aloud....................................................27

Cognitive Orientation to daily Occupational Performance..........29

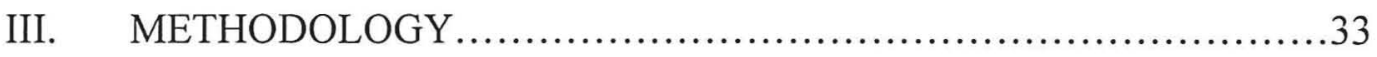

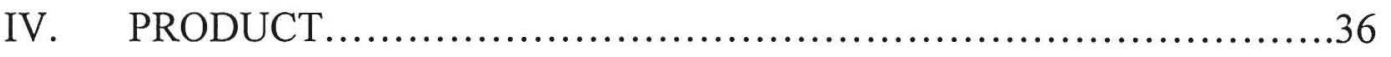

Theoretical Design...................................................

Conclusion..............................................................

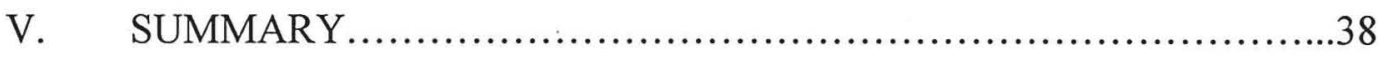

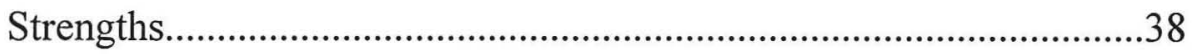

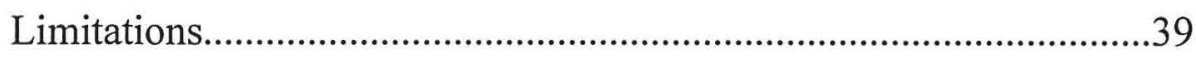

Proposal for Implementing the Project.................................................40

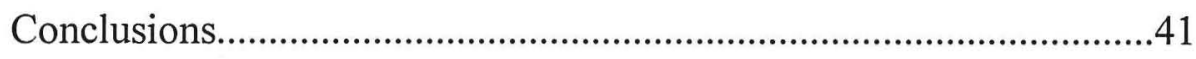

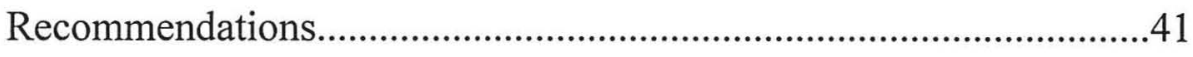

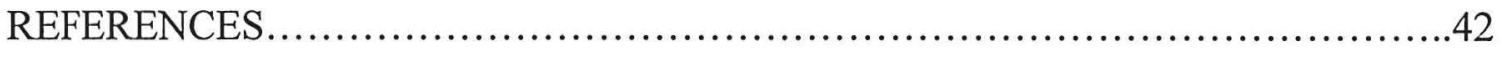

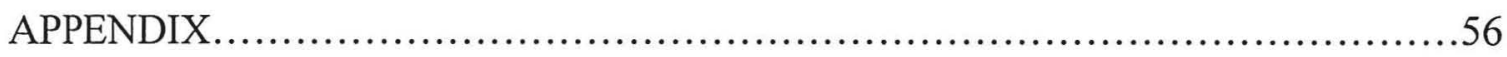




\begin{abstract}
Problem: School-based occupational therapists have reported barriers to working with children with psychosocial needs including a limited knowledge of psychosocial methods (Barnes, Beck, Vogel, Grice, \& Murphy, 2003; Case-Smith \& Archer, 2008). These issues prevent children with motivational and behavioral issues from receiving the best care possible and, in some cases, from receiving therapy at all.

Methods: An extensive literature review was conducted to understand current utilization of psychosocial strategies in school-based occupational therapy practice, barriers therapists experience in applying these strategies, and effective psychosocial strategies for children with motivational issues. Findings of the literature suggested that continuing education was correlated with increased confidence in employing psychosocial methods, therefore the authors decided to focus on educating therapists regarding psychosocial methods that are utilized with children.
\end{abstract}

Summary of Results: The outcome of this scholarly project was an article titled: Motivating the Unmotivated Child: Using Psychosocial Intervention Methods in the School. The difficulty occupational therapists face in using psychosocial strategies in school-based practice is illustrated in this article, as well as eight concepts that occupational therapists can apply when working to engage the unmotivated child in the therapy process.

Conclusions: The article for submission is only one step in overcoming barriers to using psychosocial strategies in school-based practice. The authors recommend providing 
further continuing education for therapists to address the use of psychosocial methods within the school system. It is also recommended that a research study be conducted in order to understand the effectiveness of the psychosocial methods in the school system. Limitations of the project include difficulty accessing the entire targeted audience. 


\section{CHAPTER I \\ INTRODUCTION}

School-based occupational therapists encounter many children who have motivational and behavioral issues (Barnes, Beck, Vogel, Grice, \& Murphy, 2003; Beck, Barnes, Vogel, \& Grice, 2006; Case-Smith \& Archer, 2008; Gutman, McCreedy, \& Heisler, 2004; McDuff, Schultz, Andersson, \& Pemberton, 2009). According to the National Dissemination Center for Children with Disabilities (2010), during 2003-2004, greater than 484,000 children and youth with emotional disturbance received special education services. According to Barnes et al. (2003) and Case-Smith and Archer (2008), occupational therapists are addressing some of the psychosocial performance skills of school children, however much less often than other performance skill areas. Schoolbased occupational therapists have addressed attention span, self-control, organizational skills, managing transitions, interpersonal skills, and social conduct (Barnes et al., 2003; Case-Smith \& Archer, 2008). Children with physical disabilities also display psychosocial issues and may be less motivated than their typically developing peers (Majnemer, Shevell, Law, Poulin, \& Rosenbaum, 2010; Vitulano, 2003).

However, these therapists feel ill-prepared to use psychosocial strategies in practice. According to Barnes, Beck, Vogel, Grice, \& Murphy (2003), 72.9\% of occupational therapists surveyed indicated feeling inadequately prepared to work with emotionally disturbed children. Practicing therapists report the complexity of using psychosocial interventions with children for various reasons including therapist's feelings 
of inadequate psychosocial knowledge (Barnes et al., 2003; Beck et al., 2006; Case-Smith \& Archer, 2008; Gutman et al., 2004; McDuff et al., 2009). Consequently, many of these children may be discharged from therapy and fail to meet the desired outcomes (Koller \& Bertel, 2006; Nielsen, 2011).

The purpose of this scholarly project is to increase school-based occupational therapists awareness of psychosocial strategies that can be used to motivate children and regulate their behavior so that children are more likely to meet intended outcomes. "Motivating the Unmotivated Child: Using Psychosocial Intervention Methods in the School" presents the extent of the problem and aims to provide occupational therapists with an overview of potential strategies to use with these children and resources to further investigate those strategies.

The Model of Human Occupation (MOHO) was utilized to guide our scholarly project because of the assumptions made about the influence of motivation on human occupation. Gary Kielhofner began his work on MOHO taking concepts from his mentor Mary Reilly (Cole \& Tufano, 2008). MOHO is a conceptual model of practice that is systematic and holistic. Kielhofner (2009) suggests that there are three interrelated parts that lie within each person and interact with the environment. Those parts are volition, habituation, and performance capacity. Kielhofner (2009) defines volition as the motivation a person has for occupation. He defines habituation as the roles and routines people use to organize their lives, and performance capacity as the underlying ability for performance (Kielhofner, 2009). Kielhofner (2009) identifies that motivation can be affected by values and interests a person holds. Within the environmental subsystem of Kielhofner's model contains several dimensions. These environmental dimensions 
include physical, social, cultural, economic, and political. This model proposes that: (a) a person's characteristics and environment are connected and dynamic; (b) occupation reflects and is influenced by the person's characteristics and the environment; and (c) a person's characteristics are preserved and altered through engagement in occupations (Kielhofner, 2009).

Kielhofner (2009) suggests that as people grow and learn they begin to create their own "occupational identity" which leads them to having "occupational competence". Occupational competence, according to Cole and Tufano (2008) is the ability of a person to put what a person regards as meaningful into action. Cole and Tufano (2008) identify another key concept in Kielhofner's model as being occupational adaptation, which is the outcome of positive identity and achievement.

In addition to $\mathrm{MOHO}$, andragogy was used to guide the current project. Introduced by Malcolm Knowles, andragogy is the study of adult learning (McGrath, 2009). It proposes that adult learning is fundamentally different than that of children. The theory takes into account the various learning styles of adults and proposes methods to best meet their learning needs. One primary principle of andragogy utilized in this project is that adult learning is problem-centered versus content-oriented. This means that adults tend to learn, or seek learning opportunities, when they have a problem rather than simply 'to learn'. In conjunction, adults tend to be most interested in learning about subjects that have immediate relevance to them (McGrath, 2009). This model proposes that: (a) as a person develops, they become a self-directed human being; (b) as an adult develops, they become rich resources that are able to draw upon experience; (c) an adult's readiness to learn relates to tasks of their social roles; (d) an adult becomes more problem centered 
versus subject centered; (e) adult's motivators are mostly internal; and (f) adults must be aware of why it is necessary to learn something (Merriam, Caffarella, \& Baumgartner, 2007).

School-based occupational therapists possess the skills and psychosocial knowledge necessary to utilize psychosocial methods though potentially lack awareness of the specific intervention methods they can use (Barnes et al., 2003; Beck et al., 2006; Gutman et al., 2004). "Motivating the Unmotivated Child: Using Psychosocial Intervention Methods in the School" is an educational article that can be used as a tool to increase awareness of the psychosocial intervention methods that are supported within the school system.

\section{Key Concepts/Terminology}

Psychosocial- AOTA (2004) identifies psychosocial as relating to intrapersonal, interpersonal, and social experience and interactions that influence occupational behavior including aspects of occupation that encompass the "psychosocial, cognitive, social, cultural, and spiritual aspects of occupation" (p. 669).

Psychosocial Intervention Methods- For the purposes of this paper, psychosocial intervention methods will be defined as the strategies therapists use to address psychosocial factors in intervention.

Psychosocial Knowledge- AOTA (2010) identified that psychosocial knowledge is based on principles of: "neuroscience, occupational science, pathophysiology, psychology, sociology, and therapeutic use of self” (p. 188). Concepts addressed include "motivation, self-efficacy, identity, self-concept, self-esteem, emotional regulation, coping, and balance" (p. 188). The skills required of professionals include "assessment, 
intervention planning, activity analysis, self-management strategies, and therapeutic use of self"' (p. 188).

Emotional Disturbance- Emotional disturbance means a condition exhibiting one or more of the following characteristics over a long period of time and to a marked degree that adversely affects a child's educational performance: (a) An inability to learn that cannot be explained by intellectual, sensory, or health factors. (b) An inability to build or maintain satisfactory interpersonal relationships with peers and teachers. (c) Inappropriate types of behavior or feelings under normal circumstances. (d) A general pervasive mood of unhappiness or depression. (e) A tendency to develop physical symptoms or fears associated with personal or school problems. (f) Emotional disturbance includes schizophrenia. The term does not apply to children who are socially maladjusted, unless it is determined that they have an emotional disturbance under paragraph (c)(4)(i) of this section. (IDEA, 2004, §300.8)

Holism- A way of viewing and treating a human as a whole including mind, body, and spirit (Finlay, 2001).

\section{Organization of Project}

This scholarly project is presented in five chapters. These four chapters are as follows. Chapter one is an introduction to our scholarly project including key terms and models used to guide the project. Chapter two is a review of the literature regarding psychosocial issues and strategies relevant to the school system. Chapter three consists of the methodology used for the literature review and the process used to design the final product of an article for submission to the Journal of Occupational Therapy, Schools, \& Early Intervention entitled "Motivating the Unmotivated Child: Using Psychosocial 
Methods in the School" including how the Model of Human Occupation and concepts of Andragogy guided the writing process of the article. Chapter four explains the organization of the product and how it will be used in clinical practice. Finally, chapter five presents the limitations, recommendations, and conclusion of the scholarly project. 


\section{CHAPTER II}

\section{LITERATURE REVIEW}

The purpose of this literature review was twofold, to explore the current state of school-based occupational therapy practice in terms of addressing motivational issues and to investigate options for addressing these issues. We present the following: (a) occupational therapy and its history in mental health; (b) the prevalence of psychosocial issues in children; (c) why psychosocial issues should be addressed by school-based occupational therapists; (d) current school-based occupational therapy; (e) common barriers to occupational therapists using psychosocial methods; and (f) psychosocial concepts and approaches appropriate for use by occupational therapists in the school system.

\section{Occupational Therapy Defined}

According to the American Occupational Therapy Association (AOTA, 2008), occupations are critical to a client's identity. As stated by Law, Polatajko, Baptiste, and Townsend (1997):

Occupation refers to groups of activities and tasks of everyday life, named, organized and given value and meaning by individuals, and a culture. Occupation is everything people do to occupy himself or herself, including looking after 
himself or herself (self-care), enjoying life (leisure), and contributing to the social and economic fabric of their communities (productivity) (p. 34).

Occupational therapy, then, in its simplest description, aims to "help people across the lifespan participate in the things they want and need to do through the therapeutic use of everyday activities (occupations)" (AOTA, 2012a, para.1).

The philosophy of occupational therapy depicts a profession that is holistic in nature, embracing the whole person including mind, body, and spirit (AOTA, 2008). Consequently, occupational therapists currently work in a variety of contexts including mental health, school systems, rehabilitation facilities, hospitals, home health, long-term care, and neonatal intensive care units. Settings can include rehabilitation, acute, and subacute. Despite their holistic perspective, research suggests that occupational therapists struggle to use psychosocial strategies across practice settings (Beck, Barnes, Vogel, \& Grice, 2006; Case-Smith \& Archer, 2008; Lloyd, King, \& Ryan, 2007), which impedes their ability to engage in holistic practice.

\section{History of Occupational Therapy}

Although occupational therapy is commonly associated with physical disabilities, the profession has its roots in psychosocial practice. Born out of the moral treatment movement, occupation as a therapeutic agent was first used in the treatment of mental illness (Gordon, 2009). The United States' involvement in World War I and World War II transitioned the use of occupation into physical rehabilitation. During the 1940s through 1960s many injured veterans were in need of treatment. The medical profession needed all the therapists that they could find which facilitated the transition of occupational therapists from mental health intervention to intervention focused on 
physical disabilities (Gordon, 2009). Despite the shift from mental health to physical disabilities, occupational therapists continued to be trained in psychosocial practice and work in mental health settings.

In the late 1970 's to 1980 's, there was a call for occupational therapists to move away from the reductionist medical model back to holistic treatment, concerning themselves with every aspect of the individual (Gordon, 2009). This includes examining a person's psychosocial functioning and its impact on occupational performance. Furthermore, there has been a shift back to the roots of occupational therapy in recognizing, once again, the magnitude of a person's mental health on their ability to perform daily occupations (Gordon, 2009). In its centennial vision, the AOTA (2012b) listed mental health as a focus area in order to place increased emphasis on "mental health treatment and prevention services for children, youth, [etc.]" ( para. 2).

\section{Psychosocial Issues in School-Aged Children}

Psychosocial issues are widespread in school-aged children. According to the U.S. Department of Education's (2008) Thirtieth Annual Report to Congress, emotional disturbance constitutes the fifth largest disability group in the public school system. During the 2008-2009 school year, approximately 420,000 students received special education and related services due to emotional disturbance (Institute of Education Sciences, 2011). Psychosocial behaviors exhibited by children within the school system include dysthymia, mania, physical aggression, passive aggression, physical self-injury, emotional self-injury, obsessiveness and rigidity, perseveration, dislike of novel situations, and inadequate social skills (Gutman, McCreedy, \& Heisler, 2004). 
Children with physical disabilities also display psychosocial issues and may be less motivated than their typically developing peers (Majnemer, Shevell, Law, Poulin, \& Rosenbaum, 2010; Vitulano, 2003). As well, children with emotional disturbance often have co-occurring learning disorders and sensory processing problems (Dunn, 2001; U.S. Department of Education, 2000). Issues displayed by children with learning disorders and sensory processing problems include low frustration tolerance, poor self-regulation, and self-control (Miller, Reisman, McIntosh, \& Simon, 2001).

\section{Why Psychosocial Issues Should be Addressed at School}

Psychosocial issues should be addressed in school because they impact school performance (Case-Smith \& Archer, 2008). According to Case-Smith (2005), "socially appropriate behavior is highly related to the student's academic achievement and his or her ability to succeed in environments outside school" (p. 802). Children with emotional disturbance tend to have poorer academic and social outcomes such as failing courses, lower grades, and being suspended or expelled (Wagner \& Cameto, 2004). Many perform one to two years below grade level (Reid, Gonzalez, Nordness, Trout, \& Epstein, 2004). Furthermore, as more children with various emotional needs are included in regular classrooms, greater demands are placed on special education and general education teachers (Koller \& Bertel, 2006).

Because children spend a significant amount of their day in schools, it is important that schools be involved in remediating psychosocial issues. If psychosocial issues remain unaddressed, children can carry these problems into adolescence and adulthood and then become exacerbated when they are unable to create and maintain social relationships (Gutman et. al, 2004). Children with emotional or behavioral 
disabilities are approximately 14 times less likely to finish high school than students without disabilities (Karpur, Clark, Caproni, \& Sterner, 2005). Not only are dropout rates consistently higher among students with emotional or behavioral disabilities compared to students with other disabilities (U.S. Department of Education, 2008), but they also have higher rates of unemployment and underemployment upon leaving high school than students without disabilities or with other disabilities (Carter \& Lunsford, 2005). As a result, schools must become active partners in addressing the mental health needs of children (President's New Freedom Commission on Mental Health, 2003).

\section{School-Based Occupational Therapy}

Occupational therapy is included as a related service under the Individuals with Disabilities Education Act (Individuals with Disabilities Education Act [IDEA], 2004) Part B which regulates special education services for children within the school system. Occupational therapists that work in the school system provide services to children that target: "(a) improving, developing, or restoring functions impaired or lost through illness, injury, or deprivation; (b) improving ability to perform tasks for independent functioning if functions are impaired or lost; (c) preventing, through early intervention, initial or further impairment or loss of function"(IDEA, 2004, § 300.34). These practitioners serve children in many of the 13 categories outlined by IDEA, including emotional disturbance (IDEA, 2004, § 300.8). Surveys of school-based occupational therapists reveal that therapists frequently address handwriting, sensory processing, perceptual skills, and gross and/or fine motor skills (Frolek-Clark, 2001; Gutman et al., 2004; Argabrite-Grove, 2002). While some practitioners are addressing psychosocial issues, therapists address 
these issues with much less frequency (Barnes, Beck, Vogel, Grice, \& Murphy, 2003; Case-Smith \& Archer, 2008).

\section{Addressing Psychosocial Issues}

There are several reasons why school-based occupational therapists should address psychosocial issues. As indicated above, school performance, the focus of occupational therapy services, can be negatively impacted by psychosocial issues, thus these problems would fall under a school-based occupational therapists scope of practice. Additionally, occupational therapists are one of the few professions on the school team whose education equips them in mental health promotion, prevention, and intervention (AOTA, 2010).

Occupational therapy, historically, has served many individuals with emotional and psychosocial disorders, though children and adolescents with emotional disturbance appear to be underserved by occupational therapists (Frolek-Clark, 2001). According to Barnes et al. (2003) and Case-Smith and Archer (2008), occupational therapists are addressing some of the psychosocial performance skills of school children, however much less often than other performance skill areas. School-based occupational therapists have addressed attention span, self-control, organizational skills, managing transitions, interpersonal skills, and social conduct (Barnes et al., 2003; Case-Smith \& Archer, 2008).

Occupational therapists likely encounter many children with psychosocial issues, including children seen for other disabilities (Majnemer et al., 2010; U.S. Department of Education, 2001; Vitulano, 2003). No matter the reason that the child is referred to occupational therapy services, it is important that occupational therapist use psychosocial strategies to address each child holistically. As the AOTA (2004) asserts, "psychosocial 
dimensions of human performance are fundamental to all aspects of occupation and occupational therapy, with every client, and across all practice settings" (p. 669).

\section{Barriers to Using Psychosocial Intervention Methods}

Practicing therapists report that using psychosocial intervention methods with children is challenging due to several barriers they face. Barriers identified by therapists included: (a) feeling that they have an inadequate knowledge base, (b) working with parents and teachers, (c) role confusion, and (d) motivation of the child (Barnes et al., 2003; Beck et al., 2006; Case-Smith \& Archer, 2008; Gutman et al. 2004; McDuff, Schultz, Andersson, \& Pemberton, 2009). These barriers may impede the likelihood that school-based occupational therapists will effectively work with children who struggle with psychosocial issues.

Although occupational therapy education includes psychosocial knowledge and skills (AOTA, 2004), therapists continue to report feeling that they have an inadequate knowledge base (Barnes et al., 2003; Beck et al., 2006; Gutman et al., 2004). However, in a study directly measuring knowledge school-based occupational therapists did have an adequate amount of knowledge (Nielsen, 2011), suggesting a potential for other factors that may interfere with not using those skills or knowledge with children.

Another obstacle cited by school-based occupational therapists is working with parents and teachers (Barnes et al., 2003; Case-Smith \& Archer, 2008). Therapists have reported concerns about lack of communication from parents on important decisions about their child's treatment (Nielsen, 2011). While collaborating with teachers can be a positive experience, this relationship has also produced frustration, such as when there is a lack of follow through on therapist recommendations (Nielsen, 2011). 
Role confusion has also posed as an obstacle for occupational therapists addressing psychosocial issues at school (Barnes et al., 2003; Case-Smith \& Archer, 2008). Many professionals do not know occupational therapy has a role in addressing the psychosocial needs of children (Case-Smith \& Archer, 2008). This may lead to a child not being referred to occupational therapy. Furthermore, role confusion within the profession itself can serve as a barrier. Lloyd et al. (2007) reported that even within mental health settings, occupational therapists struggle with role identification, thus it is not surprising that this issue plagues school-based therapists as well.

Given the barriers of (a) feeling that they have an inadequate knowledge base, (b) working with parents and teachers, (c) role confusion, and (d) motivation of the child, it is important that as a profession we acknowledge the importance of addressing psychosocial issues and advocate for these children and for providing those services. These barriers may ultimately lead to falling short of the child's potential in therapy, or the child may be prematurely discharged from therapy (Nielsen, 2011). McDuff et al. (2009) discussed the need for occupational therapy continuing education on psychosocial strategies. Beck et al. (2006) completed a study in which a practicing therapist stated that continuing education did not begin to touch the psychosocial needs of children in the school system. Nielsen (2011) found that school-based therapists' confidence in addressing psychosocial issues relied on being able to reference continuing education opportunities. These findings suggest those occupational therapists desire valuable continuing educations in order to gain confidence yet are finding it difficult to obtain the education they need. 


\section{Interventions}

The key elements of occupational therapy, focusing on the client and occupationbased interventions, are the key to motivation. Interventions school-based occupational therapists use to address psychosocial issues include sensory strategies, behavioral-based strategies, preventative strategies, modeling, visuals, occupation-based interventions, and a client-centered focus (Nielsen, 2011). Gutman et al. (2004) further illustrated the usefulness of client-centered interventions that begin by building a trusting relationship, helping the child identify the dysfunctional behaviors, helping the child manage emotions and impulses, helping the child tolerate change, and helping the child learn social skills. Barnes et al. (2003) described several occupation-based interventions used with children with emotional disturbance such as arts and crafts, school work tasks, environmental modifications, and social skills.

The subsequent portion of this literature review will address the psychosocial strategies listed above, including occupational therapy treatment approaches for children with motivational and behavioral issues within the school-based setting. The following content will cover a vast variety of approaches that can be used with these children. First, the important concepts of self-determination, self-regulation, and cognitive-behavioral theory are outlined. Then, specific programs are discussed.

\section{Concepts}

\section{Self-determination.}

Several researchers have focused their efforts on creating protocols and programs that target motivation and occupational performance through increasing students' self- 
determination. Field, Martin, Miller, Ward, and Wehmeyer (1998) describe selfdetermination as:

A combination of skills, knowledge and beliefs that enable a person to engage in goal-directed, self-regulated, autonomous behavior. An understanding of one's strengths and limitations together with a belief in oneself as capable and effective are essential to self-determination. When acting on the basis of these skills and attitudes, individuals have greater ability to take control of their lives and assume the role of successful adults in our society (p.2).

Goals play an integral role in self-determination. Multiple studies have found that when a person is involved in choosing their own goals, they will have increased motivation (Corker \& Donnellan, 2012; Fu, Richards, \& Jones, 2009; GómezMiñambres, 2012; Siegfried, 2011) and more success in attaining these goals (Fu et al., 2009; Moeller, Theiler, \& Wu, 2011; Siegfried, 2011). Both of the programs described below involve having children and adolescents set their own goals in an effort to increase motivation and self-determination.

\section{Self- Regulation.}

Self-regulation is the ability to adaptively monitor and control oneself (Bronson, 2000; Ning \& Downing, 2010). The term encompasses the self-control of emotions, behaviors, and cognitions (Bronson, 2000). Self-regulation has been associated with adaptive behaviors such as positive work habits and engagement in learning (RimmKaufman, Curby, Grimm, Nathanson, \& Brock, 2009); emerging literacy, vocabulary, and math skills (McClelland, Cameron, Connor, Farris, Jewkes, \& Morrison, 2007); positive social outcomes such as adaptability and social skills (Aro, Eklund, Nurmi, \& 
Poikkeus, 2012) and the ability to control one's impulses and delay gratification (Sethi, Mischel, Aber, Shoda, \& Rodriguez, 2000).

Self-regulation also appears to have a reciprocal relationship with motivation, where use of self-regulation strategies influences motivation and vice versa (Bronson, 2000; Ning \& Downing, 2010). Techniques are available to facilitate the development of self-regulation, such as by helping children identify their emotions and cognitions to regulate their behavior. Two programs developed by occupational therapists to facilitate the development of self-regulation are the Alert Program ${ }^{\circledR}$ (Williams \& Shellenberger, 1996) and Zones of Regulation® (Kuypers, 2011).

\section{Cognitive behavioral theory.}

Cognitive behavioral therapy (CBT) puts a focal point on the relationships between thoughts, feelings, and behaviors by examining negative thought processes that lead to maladaptive behaviors (Johnston, 1987). Through CBT techniques, certain skills are relearned such as effective communication, regulation of emotions, and problem solving. There are many different techniques that make up cognitive behavioral therapy, though they all have three core principles in common. The three principles include: "(1) cognitive activity affects behavior, (2) cognitive activity can be altered and modified, and (3) desired behavior change may be effected through cognitive change" (Dobson, 2010, p. 4).

Many psychosocial skills can be addressed using CBT including, but not limited to, social skills, problem-solving skills, and assertion training (Johnston, 1987). When examining social skills, a therapist trained in CBT techniques would examine non-verbal communication, gestures, tone of voice, and appropriate ways to begin and end 
conversations. Assertion training includes behavioral and cognitive techniques such as role playing, giving and receiving feedback, difference between assertive and aggressive communication styles, and compromising. Problem solving CBT techniques can include defining the problem, brainstorming solutions, step-by-step planning, and following through with the action (Johnston, 1987).

Some basic strategies used by cognitive behaviorists include psychoeducation, social learning theory, biofeedback, and self-control (Bruce \& Borg, 2002). According to Bruce and Borg (2002), psychoeducation is the process by which an individual focuses on expanding their knowledge base in order to change thoughts about themselves from incapable to capable. Bruce and Borg (2002) also identify self-control as the ability of a person to influence themselves versus being influenced by outside reinforcers. Social learning theory was introduced by Bandura and functioned on the premise that learning is a result of interactions between person, their behavior, and the environment. Biofeedback is a process by which an individual utilizes equipment in order to reveal physiological events (Bruce \& Borg, 2002).

One example of a $\mathrm{CBT}$ approach is the $\mathrm{ABC}$ method proposed by Beck (Cole \&Tufano, 2008). Beck brought some methods from his “ABC" techniques. Beck's ABC method included the following: (a) activating event, (b) beliefs about events, and (c) response. Ellis's Rational Emotive Therapy (Cole \& Tufano, 2008) built on Beck's ABC method, adding the disputing of irrational thoughts and the effects on new thoughts. Albert Ellis also brought cognitive restructuring into the forefront of cognitive therapy, which in turn added to CBT techniques. Cognitive behavioral therapy was aimed at returning to holistic practice by placing responsibility in the person's hands, for example, 
using techniques such as, self-regulation, self-monitoring, and self- reinforcement (Cole $\&$ Tufano, 2008).

Dobson (2010) identified CBT as one of the leading psychosocial methods used with the adult population. While CBT has growing evidence to support its use with children, there are limited resources of empirical evidence to support its use within the school setting (Mennuti, Freeman \& Christner, 2006). Mennuti et al. (2006) identifies the school system as playing a critical role in the emotional, cognitive, behavioral, and interpersonal development of children, making it an opportune place to employ strategies of CBT in order to address the "whole child" and their needs. Ollendick and King (2004) identify that effective and well-established treatments for children are based upon principles of behavioral and cognitive behavioral therapy, though continued research needs to be completed in order to cultivate evidence. The Substance Abuse and Mental Health Services Administration (SAMHSA, 2010) completed a report providing information on the use of Cognitive Behavioral Intervention for trauma in schools. This intervention program provides individualized intervention within the school system to children s aimed at reducing post-traumatic stress, depression, and behavioral problems by increasing coping skills after trauma. This program has been tested with children in grades 3-8 and provided initial findings of reduction of symptoms. SAMHSA (2002) also completed a report to congress that identified that $\mathrm{CBT}$ is an effective treatment intervention for children and adolescents with co-occurring mental health and substance abuse disorders.

One possible reason CBT is not being utilized within the school system is that cognitive behavioral therapists must be trained. Cognitive behavioral therapy is made up 
of many individualized treatment techniques based on the person being treated and the diagnosis. There is no catch all method in using CBT techniques. Individualized CBT sessions can be utilized or CBT techniques can be practiced in a group setting (Dobson, 2010).

Bailey (2001) identified other CBT techniques that can be used with children, such as operant condition which includes modeling, rehearsal, prompting, and feedback, as well as coaching, self-monitoring, and self-talk. Cognitive behavioral therapists frequently assign supplementary homework usually role-playing or readings for the purposes of providing added intensity and allowing time for practice.

The combination of intervention methods one chooses is dependent upon the cognitive abilities of the client. Behavioral methods are more appropriate for children and those who struggle with abstract concepts, while cognitive strategies are often used with adults. In many instances, a mixture of intervention methods proves to be most appropriate (Duncombe, 2005). Due to this fact, there is a continuum of cognitive and behavioral techniques and while the authors of this project decided to place certain intervention methods in certain categories, they are all placed on a spectrum and may exhibit qualities of a separate category.

\section{Cognitive techniques.}

On any given day, a person subjects him/herself to many internal conversations with themselves. The majority of these internal conversations happen without conscious knowledge of the conversations. A number of those thoughts may be irrational and have no factual basis. Cognitive techniques focus on identifying those irrational thoughts and 
once that is accomplished the focus shifts to cognitively changing those thought processes (Dobson, 2010).

\section{Behavioral techniques.}

Behavioral techniques are considered part of an "action-consequence model" (Bruce \& Borg, 2002, p. 122). Because of this it is thought that managing inappropriate behaviors occurs by altering the behaviors or modifying the environment. Behavioral training, for the most part began with B.F. Skinner's use of operant conditioning as well as schedules of reinforcement and Ivan Pavlov's use of classical conditioning (Cole \& Tufano, 2008). Pavlov used a stimulus/response approach to managing behaviors. Types of behavioral therapies that are currently used in occupational therapy practice include shaping, chaining, reinforcement, and token economies (Cole \& Tufano, 2008). Techniques that have been beneficial in preventing inappropriate behaviors included scheduling, structure, and consistency. Another preventative technique includes the Alert Program ${ }^{\circledR}$ in identifying red flags of emotional and behavioral problems. Watling and Schwartz (2004) found that positive reinforcement has been used to increase positive behavior skills in many areas including social behavior, functional skills, and cognitive and language skills.

Behavioral scientists have identified many different techniques to modify behaviors. These techniques can involve shaping, chaining, extinction, modeling, and self-regulation (Bruce \& Borg, 2002). Hayward, Gale, and Eikeseth (2009) identified chaining as a process of task analysis that breaks down multistep task into smaller units that can be more easily measured and placed in succession to build up to the greater activity. Chaining can be completed in a forward or backward fashion working up to the 
task or working backwards from the activity providing reinforcement for successful completion of each task. Hayward et al. (2009) stated that chaining would be a good behavioral technique to be used with children with autism spectrum disorders. Chaining is an effective method that falls under applied behavioral analysis techniques (Hayward et al., 2009). Slocum and Tiger (2011) completed a study of backwards and forwards chaining with children with developmental and learning disabilities. This study identified that both backwards and forwards chaining were successful with children, though one was no more successful then the other. Hur and Osborne (1993) completed similar study with adults with mild mental retardation demonstrating the effectiveness of chaining, though again being unable to find which one was more successful with the adult population.

Bruce and Borg (2002) identify shaping as a technique utilized to teach new, unnatural behaviors by providing rewards for wanted behavior. Cole and Tufano (2008) identified extinguishing as a process of eliminating an unwanted behavior by not providing rewards or reinforcers. Cole and Tufano (2008) also identify the support for behavioral techniques within the context of schools through rewards and privileges (operant conditioning) to reinforce successes.

\section{Specific Programs}

\section{Alert Program ${ }^{\circledR}$.}

The Alert Program ${ }^{\circledR}$ (Williams \& Shellenberger, 1996) combines sensory strategies with cognitive strategies to approach emotion regulation (Maas, Mason, \& Chandler, 2008). Williams and Shellenberger (1996) developed the Alert Program ${ }^{\circledR}$ which uses three different speeds as metaphors to explain how a child's engine runs. 
These speeds are high, low, and just-right. When an engine is running too high the child is considered agitated, wild, or hyper. On the contrary, when an engine is running low the child is considered lethargic, sluggish, spacey, and lackluster. When a child has a high or low engine, completing any task will take longer and will be more difficult. When a child has a just right engine the task will be easier and take less time to finish. A child will have an easier time playing and getting along with others when he/she is has a just right engine. High and low engines may occur when a child has sensory information that they are unable to process. Strategies to use to aid in regulating a child's engine are put something in your mouth, look, listen, touch, and move (Williams \& Shellenberger, 1996).

The Alert Program $®$ (Williams \& Shellenberger, 1996) is taught in three stages. The first stage of the program is the therapist's opportunity to inform the child to the fact that everyone has different levels of alertness, taking the time to distinguish between engine levels. At this point the child will begin to identify his/her own engine level. During the second stage of learning the Alert Program ${ }^{\circledR}$, the child will be introduced strategies to regulate emotions. Toward the end of stage two, the child will begin to make preferences towards certain regulatory strategies. Moving into stage three the child and therapist will discuss those strategies and there use within various settings and contexts. These strategies can and need to be used with the child in collaboration with teachers, parents, principles, and even occupational therapists (Salls \& Bucey, 2003). By having people modeling how their engine runs, it helps the child grasp the concepts more quickly. 
The Alert Program ${ }^{\circledR}$ has effectively been used for children with emotional disturbance (Maas et al., 2008; Barnes, Vogel, Beck, Schoenfeld, \& Owens, 2008; Barnes, Schoenfeld, Garza, Johnson, \& Tobias, 2005). Barnes et al. (2008) conducted a study in which they utilized Alert Program ${ }^{\circledR}$ in the classroom setting utilizing a pretestposttest method. Results of the study point to the Alert Program contributing to increased sensory processing skills as measured utilizing the Sensory Profile (Dunn, 1999a). A study by Maas et al. (2008) was conducted in group sessions that were 30 minutes a week for 10 weeks. Following the intervention portion of this study, researchers asked teachers how often children continue to implement strategies from the Alert Program ${ }^{\circledR}$. The teachers reported children utilizing strategies $75 \%$ of the time and also reported that children were easier to redirect when they become angry. In a study by Barnes et al. (2003), researchers distributed surveys to school-based occupational therapists in order to determine the appropriateness, extent, and types of services that are provided within the school system to children with emotional disturbance. Results of the study revealed that $28.6 \%$ of respondents used group intervention methods and the most common group interventions included sensory modulation groups which included the Alert Program ${ }^{\circledR}$. Wells, Chasnoff, Schmidt, Telford, and Schwartz (2012) completed a study in which they determined that the Alert Program ${ }^{\circledR}$ was effective for children who have fetal alcohol syndrome and difficulties with self-regulation. This study was completed in groups including parent(s) and child and was conducted by an occupational therapist though out a 12-week session.

Barnes et al. (2005) completed a study with participants being three boys, ages 910 years old. These boys were in special education and classified as having "emotional 
disturbance" and low to normal intelligence. Barnes et al. (2005) utilized the Alert Program ${ }^{\circledR}$ in individualized sessions outside of the classroom setting three days a week each in 30 minute sessions. This continued for seven weeks. Results of the study indicated that these three participants demonstrated improvements in classroom behaviors. Barnes et al. (2005) also utilized this study to identify the relationship between sensory processing and the Alert Program. Results of the study point to the Sensory Profile (Dunn, 1999a) as being an effective tool to use at the same time as the Alert Program $($ as it can guide occupational therapist in which Alert Program $®$ strategies to use. Though this study demonstrated limited generalization secondary to the small sample size, the results of the study provide a starting point for further research.

\section{Zones of Regulation®.}

Zones of Regulation ${ }^{\circledR}$ is another self-regulation program that is created by an occupational therapist (Kuypers, 2011). Kuypers' (2011) work expands on that of Williams and Shellenberger's Alert Program ${ }^{\circledR}(1996)$ and Dunn Buron, and Curtis's Incredible 5-Point Scale (Dunn Buron \& Curtis, 2003), incorporating Social Thinking concepts from the work of Winner $(2000 ; 2005 ; 2007)$. The program includes more cognitive strategies than the Alert Program ${ }^{\circledR}$ and helps students to identify triggers, identify their self-talk, label the size of their problems in order to respond appropriately, and understand social expectations and the social implications of their behavior (Kuypers, 2011).

Zones of Regulation ${ }^{\circledR}$ facilitates students' ability to categorize their alertness into four different "zones" (Kuypers, 2011). These zones are labeled by the colors blue, green, yellow, and red. The Blue Zone is indicative of low alertness and feelings of 
sickness, being tired, and being bored. The Green Zone is illustrated by a child who is happy, focused, and content. This is the desired zone as it means having control over one's body. The Yellow Zone describes a heightened state of alertness in which the person is beginning to lose some control. Feelings experienced in the Yellow Zone include stress, anxiety, silliness, and nervousness. The Yellow Zone is an expansion of the three categories used in the Alert Program ${ }^{\circledR}$ and allows for more sensitive measurement of the student's level of alertness and self-control. The Red Zone is comprised of behavior that is considered to be out of control such as anger, rage, devastation, and terror. The colors of the zones relate to traffic signs the green, yellow, and red of a stop light and the blue of a rest stop sign (Kuypers, 2011).

Over the course of 18 sessions, 30 to 60 minutes in length, the Zones of Regulation ${ }^{\circledR}$ curriculum uses these "zones" to teach children to identify when they are becoming less regulated and reflect on how their actions affect others (Kuypers, 2011). Students using Zones of Regulation ${ }^{\circledR}$ are educated on the way different emotions look

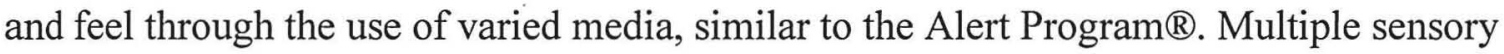
and thinking strategies are taught and utilized by children in order to regulate their mood and level of alertness. Intervention can be done individually or in groups of students who have similar abilities. The sequence of the lessons is introducing the zones, presenting the regulation tools, and finally teaching why, when, and how to use the tools (Kuypers, 2011).

The Zones of Regulation $($ is particularly suited for school-based occupational therapists. Kuypers (2011) suggests it is suited for school use as the manual is userfriendly and written so that it can be understood and implemented by the average person. 
It uses strategies that many occupational therapists are likely to be familiar with, including sensory techniques; and Kuypers (2011) provides suggestions for adapting the activities to meet the needs of different age groups and ability levels. As a bonus for professionals wanting to implement The Zones of Regulation ${ }^{\circledR}$ in a school setting, Kuypers (2011) even proposes several self-regulation goals that can be easily adapted and used for individualized education plans. One drawback of the Zones of Regulation ${ }^{\circledR}$ is that the program does not have any research on the effectiveness or its use, as it is a fairly new technique. However, a program that it is based on (i.e., the Alert Program $®$ ) and cognitive behavioral strategies, which have been researched. As mentioned above, the usefulness of the Alert Program ${ }^{\circledR}$ has been demonstrated in improving classroom behaviors (Barnes et al., 2005), such as ability to redirect the child (Maas et al., 2008).

\section{Think Aloud.}

The field of psychology has developed a method that uses introspection to address problem solving. This method focuses on the child "thinking aloud" to solve problems and is based upon the Meichenbaum's Cognitive Behavior Modification (Bruce \& Borg, 2002). Problem-solving occurs in situations in which a person has no memory of how to respond to a certain situation. Problem solving is considered a cognitive process that requires concentration and reflection on the steps necessary to make a decision. The Think Aloud protocol utilizes a variety of factual comments and inferences in order to follow the person's thought processes and examine their critical thinking and reasoning (Gardin, 2010). The Think Aloud technique assisted children in identifying where their mistake was made when problem-solving. Gardin (2010) found that the Think Aloud 
technique aided in promoting critical thinking in college students, specifically medical and nursing students, though it took much planning and preparation.

Research has been completed on the use of "think aloud" with children for the purposes of reading comprehension, mostly. Baumann, Jones, and Seifert-Kessell (1993) found that utilizing Think Aloud worked to help children to monitor reading comprehension. Baumann et al. (1993) also recommended utilizing "social construction think alouds" (pg.192) or in other words, groups in order to increase facilitation of comprehension of written text utilizing thinking aloud with multiple individuals.

Berne (2004) identified that research in continuing to grow with regards to reading instruction for children, though there has not been much in the way of educational research regarding the specific ways that adult learners develop their skills. In Berne's (2004) study, the intervention used was "think alouds" with the adult population every other week for 15 weeks. This study yielded limited evidence to support the use of "think alouds" with the adult population, though Berne thought perhaps this was secondary to the short duration of the utilization of the Think Aloud protocol leading the students to not have this in their repertoire of reading strategies. With further examination of utilizing the Think Aloud protocol, Berne (2004) was able to identify that adult students felt that this method of learning made them feel "childish" (pg. 170). Berne (2004) concluded that with primary and secondary students, the Think Aloud protocol could be practiced and eventually become a natural strategy for reading comprehension, though adult populations may not have that comfort level. More research is necessary in order to create more evidence to support Berne's ideas as well as increase evidence of strategies to improve adult learning. 


\section{Cognitive Orientation to daily Occupational Performance (CO-OP).}

Created by occupational therapists, Cognitive Orientation to Daily Occupational Performance (CO-OP) is an intervention approach in which children learn strategies to improve occupational performance (Polatajko et al., 2001b). Originally designed for children ages 7 to 12 who have developmental coordination disorder, the approach focuses on skill acquisition by enabling children to set and obtain their own occupational goals and providing the appropriate level of guidance to get them there (Polatajko, Mandich, Miller, \& Machnab, 2001a).

As mentioned above, opportunities for self-directed learning enhance selfdetermination which has important implications for motivation (Wehmeyer, Palmer, Agran, Mithaug, \& Martin, 2000). A key to addressing self-determination through COOP is allowing children to set and work toward their own goals (Polatajko \& Mandich, 2005). Engaging children in this process ensures children find the goals to be meaningful, increasing motivation to learn skills, use skills beyond the context of therapy, and generalize learning to other skills (Polatajko \& Mandich, 2005).

CO-OP has shown great promise in aiding children with occupational performance deficits obtain the skills they need (Chen \& Cohn, 2003; Polatajko et al., 2001a; Missiuna et al., 2010; Rodger, Springfield, \& Polatajko, 2007; Rodger \& Vishram, 2010; Ward \& Rodger, 2004). While it was originally developed and researched for children with developmental coordination disorder (Polatajko et al., 2001a), researchers are applying it to other populations with motor skill deficits such as children with acquired brain injury (Missiuna et al., 2010) and even children who have Asperger's syndrome (Rodger et al., 2007). Ward and Rodger (2004) have found the 
protocol to have benefits for children as young as five. Rodger and Vishram (2010) have even taken the protocol one step further and adapted it to work on social skill deficits with children who have Asperger's syndrome. Chen and Cohn (2003) cite CO-OP's potential to address social skill deficits with children who have developmental coordination disorder.

Similar to Think Aloud, CO-OP draws heavily from the work of Meichenbaum (1977) and other theorists to provide a foundation for its protocol (Missiuna, Mandich, Polatajko, \& Malloy-Miller, 2001; Bruce \& Borg, 2002). Meichenbaum proposed that children could use cognitive strategies to regulate their own behavior. He described a process in which children would develop a goal, create a plan to reach that goal, carry out that plan, and evaluate the results. This strategy constitutes the global cognitive strategy of CO-OP, Goal-Plan-Do-Check, and is used throughout intervention to support skill acquisition. The creators of CO-OP also incorporated the concepts behind Meichenbaum's scaffolding, Feurstein and colleagues' meditational techniques, and Pressley and colleague's guided discovery to define the role of the therapist during intervention (Missiuna et al., 2001).

Like all cognitive strategies, $\mathrm{CO}-\mathrm{OP}$ has prerequisites that must be met in order for the intervention to be beneficial (Polatajko et al., 2001b). First, a child must be able to complete the Canadian Occupational Performance Measure (COPM) which requires cognitive and language abilities to identify areas of dissatisfaction and to set goals concerning them. A child must further be able to attend and respond to the therapist during therapy, as well as have the potential to perform the task and the motivation to 
learn the skills (Polatajko et al., 2001b). As discussed earlier, child-chosen goals along with other features of the protocol assist with motivation.

An essential component of $\mathrm{CO}-\mathrm{OP}$ is the use of guided discovery (Polatajko \& Mandich, 2005). Therapists must be purposeful in their actions and reactions while using this approach. Polatajko and Mandich (2005) name four strategies for employing guided discovery using CO-OP: (a) One Thing at a Time!; (b) Ask, Don't Tell!; (c) Coach, Don't Adjust!; and (d) Make It Obvious! These strategies support the child's own use of strategies to acquire skills and confront future problems.

In addition to the global strategy of Goal-Plan-Do-Check, CO-OP also utilizes eight domain specific strategies (Polatajko et al., 2001b). The strategies assist with solving specific performance problems and include (a) body position, (b) task specification/modification, (c) feeling the movement, (d) verbal motor mnemonic, (e) verbal rote script, (f) verbal instruction, (g) verbal self-instruction, and (h) attention to doing (Polatajko et al., 2001b, p. 117). In adapting the protocol to meet the social needs of children with Asperger's syndrome, Rodger and Vishram (2010) created new domain specific strategies such as transitional supports, affective supports, attending, taskspecification, task modification, and supplementing task knowledge.

One of the primary barriers to implementing CO-OP in a school setting is the extensive amount of parental involvement that the program requires. It may not be feasible to expect this level of participation from the parents both in coming to school therapy sessions and in following through with strategies at home. This limitation may be overcome to some degree with involvement from teachers or aids that could assist the child in using the strategies throughout the school day. 
The other limitations of the CO-OP program are similar to any cognitive strategy, one must have sufficient cognitive abilities to learn and apply the strategies in a meaningful way. Furthermore, while much research has been done on the approach, the quality of the support provided by these studies is lacking. Many are limited by small samples sizes and are not directly replicated by other research. Overall, however, CO-OP and the techniques used within the approach provide an applicable and evidence-based method for skill acquisition (Chen \& Cohn, 2003; Missiuna et al., 2010; Polatajko et al., 2001a; Rodger et al., 2007; Rodger \& Vishram, 2010; Ward \& Rodger, 2004.) 


\section{CHAPTER III METHODOLOGY}

The process of this scholarly project began by the authors collaborating and determining common interest areas. Due to personal experience with children and psychology, the authors decided upon the topic of the psychosocial intervention methods that are utilized in the school system. A literature review was conducted to attain information about: (a) the prevalence of psychosocial issues in children; (b) why psychosocial issues should be addressed by school-based occupational therapists; (c) current school-based occupational therapy; and (d) common barriers to occupational therapists using psychosocial methods. This literature was found in journal articles, textbooks, and websites.

While compiling the literature review, we found that many children who have motivational and behavioral issues are discharged from therapy or fail to meet the desired outcomes (Nielsen, 2011). Furthermore, school-based occupational therapists reported many barriers to using psychosocial interventions, including inadequate knowledge of the topic (Barnes, Beck, Vogel, Grice, \& Murphy, 2003; Beck, Barnes, Vogel, \& Grice, 2006; Case-Smith \& Archer, 2008; Gutman, McCreedy, \& Heisler, 2004; McDuff, Schultz, Andersson, \& Pemberton, 2009). Thus, our findings compelled us to search for psychosocial concepts and approaches appropriate for use by occupational therapists in the school system. 
Following the literature review, we determined that our project would be an educational article addressing the critical need of psychosocial interventions for school based occupational therapists. An article was found from the Journal of Occupational Therapy, Schools, and Early Intervention that discussed self-determination and was similar in formatting to the article we hope to publish with the same journal. This article was used as a resource to guide our writing and formatting throughout our article.

The Model of Human Occupation (MOHO) was chosen to guide the development of the article. This model was chosen since it addresses participation and adaptation in various environments (Kielhofner, 2009). We chose to address methods used within the school system as children spend a great deal of time within the school context while they are growing and learning. Kielhofner (2009) suggests that a person's characteristics are dynamic and related to the environment and engagement in occupations.

Furthermore, volition is a one of the three interacting building blocks that Kielhofner (2009) identifies in MOHO. Volition is defined as "the process by which people are motivated toward and choose the activities they do" (Kielhofner, 2009, p.150). This concept provides the backbone of this scholarly project as motivating children to help them achieve better outcomes is the underlying purpose. Secondly, in order to help therapists use the information available to them, the article must motivate them as adult learners.

Due to the characteristics of the target population, andragogy, the study of adult learning, was also used to guide the article's development. The theory takes into account the various learning styles of adults and proposes methods to best meet their learning needs (McGrath, 2009; Merriam, Caffarella, \& Baumgartner, 2007). Andragogy proposes 
that adults tend to learn or seek learning opportunities, when they have a problem rather than simply "to learn". It also proposes that adults tend to be most interested in learning about subjects that have immediate relevance to them (McGrath, 2009; Merriam, Caffarella, \& Baumgartner, 2007). Paradoxically, adult learners can also be resistant to change and anxiety can decrease their motivation to learn (Kessels, 2003). While adult learners tend to be more independent, they often require structure, guidance, and clarity. Therefore, to make this project most useful for the average occupational therapy practitioner, it needed to address a problem of relevance to that population in a clear and structured manner. It also needed to capture and sustain the target population's attention. The principles of andragogy assisted in these efforts.

Throughout the literature review, it has become evident that psychosocial methods are not being addressed in the school system. There are numerous reasons that are attributed to that disuse; with one being the occupational therapist feels unprepared to treat a child's psychosocial needs. Through this scholarly project, it is our hope that occupational therapists will become familiar with psychosocial methods that can be used with children that are already on their case-load and have motivational issues, and that they are motivated to learn more in order to demonstrate increased holism and clientcentered care. 


\section{CHAPTER IV}

\section{PRODUCT}

The article, "Motivating the Unmotivated Child: Using Psychosocial Intervention Methods in the School" is aimed at providing occupational therapists with different psychosocial strategies that can be utilized in order to increase motivation of the children occupational therapists encounter in the school system. The article begins by describing reasons therapists should use psychosocial intervention methods as well as reasons therapists feel unprepared to address the psychosocial needs of the children on their caseload. Through a literature review, the authors found that continuing education increases therapist's confidence with utilizing psychosocial strategies (Nielsen, 2011). Because of this, the authors explain eight intervention strategies that can be incorporated into treatment to address the motivational issues that children face. In the final part of the article, two case studies are utilized to illustrate the implementation of these strategies.

\section{Theoretical Design}

Authors chose to use the Model of Human Occupation and Malcolm Knowles's Theory of Andragogy to guide the article development process. The Model of Human Occupation was utilized due to the impact of motivation on occupational performance. This model proposes that: (a) a person's characteristics and environment are connected and dynamic; (b) occupation reflects and is influenced by the person's characteristics and the environment; and (c) a person's characteristics are preserved and altered through 
engagement in occupations (Kielhofner, 2009). Andragogy was utilized throughout the writing process of "Motivating the Unmotivated Child: Using Psychosocial Intervention Methods in the School" as the authors realize adult learning is different then learning in children. Andragogy proposes that: (a) as a person develops, they become a self-directed human being; (b) as an adult develops, they become rich resources that are able to draw upon experience; (c) an adult's readiness to learn relates to tasks of their social roles; (d) an adult becomes more problem centered versus subject centered; (e) adult's motivators are mostly internal; and (f) adults must be aware of why it is necessary to learn something (Merriam, Caffarella, \& Baumgartner, 2007). In essence, this is an easy-to-read article that is focused on teaching adult learners different strategies to use in practice in order to motivate children.

\section{Conclusion}

"Motivating the Unmotivated Child: Using Psychosocial Intervention Methods in the School" is one resource school-based occupational therapists can use to continue their education in order to treat children with motivation issues in a more holistic and clientcentered manner. The proposed product, an article suitable for submission is presented in appendix. The article has been submitted to the Journal of Occupational Therapy, Schools, and Early Intervention. 


\section{CHAPTER V}

\section{SUMMARY}

School-based occupational therapists have reported barriers to working with children with psychosocial needs including a limited knowledge of psychosocial methods (Barnes, Beck, Vogel, Grice, \& Murphy, 2003; Case-Smith \& Archer, 2008). This barrier may prevent children with motivational and behavioral issues from receiving the best care possible, and in some cases from receiving therapy at all (Nielsen, 2011). Many occupational therapists would benefit from further information on how to work with children who have motivational and behavioral issues.

Therefore, after an extensive literature review, the authors created an article for publication presenting psychosocial strategies for motivating children in school-based occupational therapy practice. The article presents motivational concepts and applies those concepts to two case studies representing typical children on a school-based occupational therapist's caseload.

\section{Strengths}

The clinical strengths of this product are many. The article addresses the barrier of limited knowledge of psychosocial methods by presenting pertinent, evidence-based information in an easy-to-understand format. Both underlying motivational concepts and examples for application are presented in the article. In this way, readers might gain functional ideas to motivate children while understanding why those applications are 
motivating. The user-friendly table format helps to facilitate the translation of knowledge into practice. Furthermore, by reading the article, school-based occupational therapists can gain knowledge and resources to further develop this area of practice which benefits their clients and the profession as a whole.

\section{Limitations}

One of the primary limitations of this project is accessing the targeted audience. In order to effect change in how motivational and behavioral issues are dealt with by school-based occupational therapists, one must first gain access to these therapists. Furthermore, the audience for the article is primarily limited to those who have access to the journal or magazine where the article is published. This limits the effectiveness of the article to create widespread change. To combat this limitation, the authors chose to submit to journals and/or practice magazines that are also targeted at these therapists.

In completing an extensive literature review, the authors found a great deal of valuable information regarding psychosocial strategies. Secondary to the limited space available for publication, much of this information had to be condensed. The authors selected only those strategies a therapist with general psychosocial knowledge would be able to implement. Furthermore, in addressing this limitation, the authors mentioned as many additional resources within the article as space allowed. This permits therapists to follow up on the information provided and seek other learning opportunities.

Ideally, publication of the article would lead to implementation of the motivational concepts presented. Therefore, a limitation of this project is lack of information pertaining to implementation of the psychosocial concepts presented in the 
article. There are no simple or cost-effective methods to determine whether therapists read and incorporated the concepts into their daily practice.

Lastly, the authors acknowledge addressing only one barrier to using psychosocial strategies, lack of confidence/knowledge with psychosocial strategies. Many other barriers exist (Barnes, Beck, Vogel, Grice, \& Murphy, 2003; Case-Smith \& Archer, 2008).

\section{Proposal for Implementing the Project}

Since the product of this project is an article for publication, the authors intend to submit the article to journals and/or practice magazines that target school-based occupational therapists. The authors' first choice is the Journal of Occupational Therapy, Schools, \& Early Intervention because it is a peer reviewed journal that serves as a resource specifically for school-based occupational therapists. The authors' second choice is to submit the article to OT Practice, a practice magazine that targets all occupational therapy practitioners. In the event that neither of these publications accepts the article for publication, the authors intend to seek out other alternatives for publication/dissemination. Examples are the American Occupational Therapy Association conference or a state association newsletter. Regardless of where the article is ultimately published, the authors will work with the editors of that journal or magazine to alter the format of the document as needed.

As mentioned above, it is beyond the scope of this project to measure its true success, incorporation of psychosocial concepts to motivate children in school-based occupational therapy. Success of this project, thus, will be indicated by publication in a journal or practice magazine commonly read by school-based occupational therapists. 


\section{Conclusions}

After an extensive literature review, it was determined that school-based occupational therapists experience many barriers to using psychosocial strategies in practice (Barnes, Beck, Vogel, Grice, \& Murphy, 2003; Case-Smith \& Archer, 2008) to the detriment of the children on their caseload (Nielsen, 2011). Findings of the literature suggested that continuing education was correlated with increased confidence in employing psychosocial methods; therefore, the authors decided to focus on educating therapists regarding psychosocial methods that can be utilized to motivate children. The result is an article for publication in a journal or practice magazine. This article is one step in overcoming the barriers of using psychosocial strategies in practice.

\section{Recommendations}

The authors recommend continued research and education to address the use of psychosocial strategies within the school system. Multiple studies, which served as the impetus for this product, have indicated a need for continuing education on psychosocial strategies (Beck et al., 2006; McDuff et al., 2009; Nielsen, 2011). In fact, school-based therapists' confidence has been found to correlate with the ability to reference continuing education opportunities. As mentioned above, the article that resulted from this project is only one step in overcoming the barriers faced by school-based occupational therapists. Continued opportunities and resources are needed to fill the gap between existing knowledge and confidence with psychosocial strategies and the desired state of occupational therapy practice. 


\section{REFERENCES}

Alderman, M. K. (2004). Motivation for achievement: Possibilities for teaching and learning (2nd ed.). Mahwah, NJ: Erlbaum.

American Occupational Therapy Association (2004). The psychosocial aspects of occupational therapy. American Journal of Occupational Therapy, 58, 669-672.

American Occupational Therapy Association. (2008). Occupational therapy practice framework: Domain and process (2nd ed.). American Journal of Occupational Therapy, 62, 625-683. doi: 10.5014/ajot.62.6.625

American Occupational Therapy Association. (2010). Specialized knowledge and skills in mental health. American Journal of Occupational Therapy, 64(Suppl.), S30-S43. doi:10.5014/ajot.2010.64S30-64S43

American Occupational Therapy Association. (2012a). About occupational therapy? Retrieved from http://www.aota.org/Consumers.aspx

American Occupational Therapy Association. (2012b). Mental health. Retrieved from http://www..org/Practitioners/PracticeAreas/MentalHealth.aspx.

Argabrite-Grove, R.E. (2002). OT in the schools: Embracing our psychosocial roots. OT Practice, 7(6), 21-25.

Aro, T., Eklund, K., Nurmi, J. E., \& Poikkeus, A. M. (2012). Early language and behavioral regulation skills as predictors of social outcomes. Journal of Speech, 
Language, and Hearing Research, 55, 395-408. doi: 10.1044/1092-4388(2011/100245)

Bailey, V. (2001). Cognitive-behavioural therapies for children and adolescents. Advances in Psychiatric Treatment, 7, 224-232.

Bandura, A. (1977). Social learning theory. New York: General Learning Press. Bandura, A. (1997). Self-efficacy: The exercise of control. New York: Freeman.

Barnes, K. J., Beck, A. J., Vogel, K. A., Grice, K. O., \& Murphy, D. (2003). Perceptions regarding school-based occupational therapy for children with emotional disturbances. American Journal of Occupational Therapy, 57, 337-341.

Barnes, K.J., Vogel, K.A., Beck, A.J., Schoenfeld, H.B., \& Owen, S.V. (2008). Selfregulation strategies of children with emotional disturbance. Physical and Occupational Therapy in Pediatrics, 28(4), 369-387.

Barnes, K., Schoenfeld, H., Garza, L., Johnson, D., \& Tobias, L. (2005, June). Preliminary: Alert Program ${ }^{\circledR}$ for boys with emotional disturbances in the school setting. American Occupational Therapy Association School System Special Interest Section Quarterly, 12, 1-4.

Baumann J., Jones, L.A., \& Seifert-Kessell, N. (1993). Using think-alouds to enhance children's comprehension monitoring abilities. The Reading Teacher, 47 (3), 184193.

Beck, A. J., Barnes, K. J., Vogel, K. A., \& Grice, K. O. (2006). The dilemma of psychosocial occupational therapy in public schools: The therapists' perceptions. Occupational Therapy in Mental Health, 22, 1-17. 
Beckman, P. (2002). Strategy instruction. ERIC digest (Digest number E638). Arlington, VA: ERIC Clearinghouse on Disabilities and Gifted Education, Council for Exceptional Children.

Berne, J. (2004). Think-aloud protocol and adult learners. Adult Basic Education, 13(3), $153-173$.

Bronson, M. B. (2002). Self-regulation in early childhood, nature and nurture. New York, NY: The Guilford Press.

Bruce, M. A., \& Borg, B. (2002). Psychosocial frames of reference: Core for occupationbased practice. Thorofare, NJ: Slack Incorporated.

Carter, E., \& Lunsford, L.B. (2005). Meaningful work: Improving employment outcomes for transition age youth with emotional and behavioral disorders. Preventing School Failure, 49(2), 63-69.

Case-Smith, J. (2005). Occupational therapy and children. St. Louis, MO: Elsevier Mosby.

Case-Smith, J., \& Archer, L. (2008). School-based services for students with emotional disturbance: Findings and recommendations. OT Practice, 13(1), 17-21.

Chen, H.F., \& Cohn, E. S. (2003). Social participation for children with developmental coordination disorder: Conceptual, evaluation, and intervention considerations. Physical \& Occupational Therapy in Pediatrics, 23(4), 61-78.

Cimpian, A., Acre, H. M., Markman, E. M., \& Dweck, C. S. (2007). Subtle linguistic cues affect children's motivation. Psychological Science, 18, 314-316. doi: $10.1111 / \mathrm{j} .1467-9280.2007 .01896 . x$ 
Cole, M. B., \& Tufano, R. (2008). Applied theories in occupational therapy: A practical approach. Thorofare, NJ: Slack Incorporated.

Corbett, B. A., \& Abdullah, M. (2005). Video modeling: Why does it work for children with autism? Journal of Early and Intensive Behavior Intervention, 2(1), 2-8.

Corker, K. S., \& Donnellan, M. B. (2012). Setting lower limits high: The role of boundary goals in achievement motivation. Journal of Educational Psychology, 104(1), 138-149.

Cross, L.A., \& Coster, W.J. (1997). Symbiotic play language during sensory integration treatment. American Journal of Occupational Therapy, 51 (10), 808-814.

Dobson, K. (2010). Handbook of cognitive-behavioral therapies. (3 ed.). New York, NY: The Guilford Press.

Duncombe, L.W. (2005). The cognitive behavioral model in mental health. In N. Katz (Ed.), Cognition and occupation across the life span, (pp. 187-210). Bethesda, MD: AOTA.

Dunkerly, E., Tickle-Degnen, L., \& Coster, W.J. (1997). Therapist-child interaction in the middle minutes of sensory integration treatment. American Journal of Occupational Therapy, 51 (10), 799-805.

Dunn, W. (1999a). The Sensory Profile. San Antonio, TX: Psychological Corporation.

Dunn,W. (2001). The sensations of everyday life: Empirical, theoretical, and pragmatic considerations. American Journal of Occupational Therapy, 55, 608-620.

Dunn Buron, K., \& Curtis, M. (2003). The Incredible 5-Point Scale: Assisting students with autism spectrum disorders in understanding social interactions and 
controlling their emotional responses. Mission, KS: Autism Asperger Publishing Co.

Eitam, B., Kennedy, P. M., \& Tory Higgins, E. (2013). Motivation from control. Experimental Brain Research, Online Publisher. doi: 10.1007/s00221-012-3370-7

El, R. P., Tillema, H., \& van Koppen, S. (2012). Effects of formative feedback on intrinsic motivation: Examining ethnic differences. Learning and Individual Differences, 22(4), 449-454. doi: 10.1016/j.lindif.2012.04.001

Field., S., Martin, J., Miller, R., Ward, M., \& Wehmeyer, M. (1998). A practical guide to teaching self-determination. Reston, VA: Council for Exceptional Children.

Finlay, L. (2001). Holism in occupational therapy: Elusive fiction and ambivalent struggle. American Journal of Occupational Therapy, 55, 268-276.

Frolek-Clark, G. (2001). Children often overlooked for occupational therapy services in educational settings. AOTA School System Special Interest Section Quarterly, 8 (3), 1-3.

Fu, F. Q., Richards, K. A., \& Jones, E. J. (2009). The motivation hub: Effects of goal setting on self-efficacy on effort and new product sales. Journal of Personal Selling \& Sales Management, 29(3), 277-292.

Gardin, F.A. (2010). The "Think Aloud" method to promote student modeling of expert thinking. Athletic Therapy Today, 15(4), 28-21.

Gómez-Miñambres, J. (2012). Motivation through goal setting. Journal of Economic Psychology, 33(6), 1223-1239.

Gordon, D. M. (2009). The history of occupational therapy. In H.S. Willard, E.B. Crepeau, E.S. Cohn, \& B. A. B. Schell (Eds.), Willard and Spackman's 
occupational therapy (11 ed., pp. 202-215). Baltimore: Lippincott Williams \& Wilkins.

Gutman, S.A., McCreedy, P., \& Heisler, P. (2004). The psychosocial deficits of children with regulatory disorders: Identification and treatment. Occupational Therapy in Mental Health, 20(2), 1-32.

Hart, W., \& Albarracin, D. (2009). The effects of chronic achievement motivation and achievement primes on the activation of achievement and fun goals. Journal of Personality and Social Psychology, 97(6), 1129-1141.

Hayward, D.W., Gale, C.M., \& Eikeseth, S. (2009). Intensive behavioural intervention for young children with autism: A research-based service model. Research in Autism Spectrum Disorders, 3(3), 571-580.

Hur, J. J., \& Osborne, S. (1993). A comparison of forward and backward training methods used in teaching corsage making skills to mentally retarded adults. British Journal of Developmental Disabilities, 77(2), 108-117.

Individuals with Disabilities Education Improvement Act. (2004). Retrieved June 15, 2012, from http://idea.ed.gov/explore/view/p/\%2Croot $\% 2$ Cregs $\% 2 C 300 \% 2 \mathrm{CA} \% 2 \mathrm{C} 300 \% 252$ $\mathrm{E} 34 \% 2 \mathrm{C}$

Institute of Education Sciences. (2011). Fast facts: Students with disabilities. Retrieved from: http://nces.ed.gov/fastfacts/display.asp?id=64

Johnston, M.T. (1987). Occupational therapists and the teaching of cognitive behavioral skills. Occupational Therapy in Mental Health, 7(3), 67-81. 
Karpur, A., Clark, H.B., Caproni, P., \& Sterner, H. (2005). Transition to adult roles for students with emotional/behavioral disturbances: A follow up study of student exiters from Steps-to-Success. Career Development for Exceptional Individuals, $28,36-47$.

Kessels, R. P. (2003). Patients' memory for medical information. Journal of the Royal Society of Medicine, 96, 219-222.

Koller, J.R., \& Bertel, J.M. (2006). Responding to today's mental health needs of children, families, and schools: Revisiting the preservice training and preparation of school-based personnel. Education \& Treatment of Children, 29(2), 197-217.

Kuypers, L. (2011). The zones of regulation. San Jose: Social Thinking.

Kielhofner, G. (2009). Conceptual foundations of occupational therapy practice (4 ed.). Philadelphia, PA: F A Davis Co.

Law, M., Polatajko, H., Baptiste, S., \& Townsend, E. (1997). Core concepts of occupational therapy. In Canadian Association of Occupational Therapists (Ed.), Enabling occupation: An occupational therapy perspective (pp. 29-56). Ottawa: CAOT Publications ACE.

Lloyd, C., King, R., \& Ryan, L. (2007). The challenge of working in mental health settings: Perceptions of newly graduated occupational therapists. British Journal of Occupational Therapy, 70(11), 470-470.

Maas, C., Mason, R., \& Candler, C. (2008). When I get mad. OT Practice, 13, 9-14. Majnemer, A., Shevell, M., Law, M., Poulin, C., \& Rosenbaum, P. (2010). Level of motivation in mastering challenging tasks in children with cerebral palsy. 
Developmental Medicine \& Child Neurology, 52(12), 1120-1126. doi:

$10.1111 / \mathrm{j} .1469-8749.2010 .03732 . \mathrm{x}$

Margolis, H., \& McCabe, P. P. (2006). Improving self-efficacy and motivation: What to do, what to say. Intervention in School and Clinic, 41(4), 218-227.

McClelland, M. M., Cameron, C. E., Connor, C. M., Farris, C. L., Jewkes, A. M., \& Morrison, F. J. (2007). Links between behavioral regulation and preschoolers' literacy, vocabulary, and math skills. Developmental Psychology, 43(4), 947-959. doi: $10.1037 / 0012-1649.43 .4 .947$

McDuff, S., Schultz, S., Andersson, E., \& Pemberton, J. (2009). Meeting the psychosocial needs of the students in special education: An ethnographic study. Journal of Occupational Therapy, Schools, \& Early Intervention, 2, 205-216.

McGrath, V. (2009). Reviewing the evidence on how adult students learn: An examination of Knowles' model of andragogy. Retrieved from ERIC database. (EJ860562).

Meichenbaum, D. (1977). Cognitive-behavior modification, an integrative approach. New York, NY: Springer.

Mennuti, R. B., Freeman, A., \& Christner, R. W. (2006). Cognitive-behavioral interventions in educational settings: A handbook for practice. New York, NY: Psychology Press.

Merriam, S.B., Caffarella, R.S., \& Baumgartner, L.M. (2007). Knowles's andragogy, and models of adult learning by McClusky, Illeris, and Jarvis. In S. Merriam, R. Cafferla, \& L. Baumgartner (Eds.), Learning in adulthood (pp. 83-104), San Fransisco, CA: John Wiley \& Sons, Inc. 
Miller, L., Reisman, J., McIntosh, D., \& Simon, J. (2001). An ecological model of sensory modulation. In S. Smith Roley, E. Blanche, \& R. Schaaf (Eds.), Understanding the nature of sensory integration with diverse populations (pp. 57-82). San Antonio, TX: Therapy Skill Builders.

Missiuna, C., DeMatteo, C., Hanna, S., Mandich, A., Law, M., Mahoney, W., \& Scott, L. (2010). Exploring the use of cognitive intervention for children with acquired brain injury. Physical \& Occupational Therapy in Pediatrics, 30(3), 205-219. doi: 10.3109/01942631003761554

Missiuna, C., Mandich, A.D., Polatajko, H.J., \& Malloy-Miller, T. (2001). Cognitive Orientation to daily Occupational Performance (CO-OP): Part I - Theoretical foundations. Physical \& Occupational Therapy in Pediatrics, 20(2), 69-81.

Moeller, A.J., Theiler, J.M., \& Wu, C. (2011). Goal setting and student achievement: A longitudinal study. The Modern Language Journal, 96(ii), 153-169. doi: 10.1111/j.1540-4781.2011.01231.x

National Dissemination Center for Children with Disabilities. (June 2010). Emotional disturbance. Retrieved from http://nichcy.org/disability/specific/emotionaldisturbance\#freq

Nielsen, S. K. (2011). A mixed-methods study examining the effectiveness of psychosocial occupational therapy preparation for therapists working with children in schools. (Unpublished doctoral dissertation). North Dakota State University, Fargo, ND.

Ning, H. K., \& Downing, K. (2010). The reciprocal relationship between motivation and self-regulation: A longitudinal study on academic performance. Learning and Individual Differences, 20, 682-686. doi: 10.1016/j.lindif.2010.09.010 
Ollendick, T. H., \& King, N. J. (2004). Empirically supported treatments for children and adolescents: Advances toward evidence-based practice. In P. M. Barrett \& T. H. Ollendick (Eds.), Handbook of interventions that work with children and adolescents: Prevention and treatment (pp. 3-25). New York, NY: John Wiley \& Sons.

Polatajko, H. J., \& Mandich, A. D. (2005). Cognitive Orientation to daily Occupational Performance with children with developmental coordination disorder. In N. Katz (Ed.), Cognition \& occupation across the life span (pp. 237-259). Bathesda, MD: AOTA Press.

Polatajko, H.J., Mandich, A.D., Miller, L.T., \& Macnab, J.J. (2001a). Cognitive Orientation to daily Occupational Performance (CO-OP): Part II - The evidence. Physical \& Occupational Therapy in Pediatrics, 20(2), 83-106.

Polatajko, H.J., Mandich, A.D., Missiuna, C., Miller, L.T., Macnab, J.J., Malloy-Miller, T., \& Kinsella, E.A. (2001b). Cogntive Orientation to daily Occupational Performance (CO-OP): Part III - The protocol in brief. Physical \& Occupational Therapy in Pediatrics, 20(2), 107-123.

President's New Freedom Commission on Mental Health (2003). Achieving the Promise: Transforming Mental Health Care in America. Final Report for the President's New Freedom Commission on Mental Health (SMA Publication NO. 03-3832). Rockville, MD: Author.

Reid, R., Gonzalez, J., Nordness, P. D., Trout, A., \& Epstein, M. H. (2004). A metaanalysis of the academic status of students with emotional/ behavioral disturbance. The Journal of Special Education, 38, 130-143. 
Rimm-Kaufman, S. E., Curby, T. W., Grimm, K. J., Nathanson, L., \& Brock, L. L. (2009). The contribution of children's self-regulation and classroom quality to children's adaptive behaviors in the kindergarten classroom. Developmental Psychology, 45(4), 958-972. doi: 10.1037/a0015861

Rodger, S., Pham, C., \& Mitchell, S. (2009). Cognitive strategy use by children with Asperger's syndrome during intervention for motor-based goals. Australian Occupational Therapy Journal, 56, 103-111. doi: 10.1111/j.14401630.2007.00719.x

Rodger, S., Springfield, E., \& Polatajko, H.J. (2007). Cognitive Orientation for daily Occupational Performance approach for children with Asperger's syndrome: A case report. Physical \& Occupational Therapy in Pediatrics, 27(4), 7-22. doi: 10.1300/J006v27n04_02

Rodger, S., \& Vishram, A. (2010). Mastering social and organizational goals: Strategy use by two children with Asperger syndrome during Cognitive Orientation to daily Occupational Performance. Physical and Occupational Therapy in Pediatrics, 30(4), 264-276. doi: 10.3109/01942638.2010.500893

Salls, J., \& Bucey, J. (2003). Self-regulation strategies for middle school students. OT Practice, 8(5), 11-16.

Sethi, A., Mischel, W., Aber, J. L., Shoda, Y., \& Rodriguez, M. L. (2000). The role of strategic attention deployment in development of self-regulation: Predicting preschoolers' delay of gratification from mother-toddler interactions. Developmental Psychology, 36(6), 767-777. doi: 10.1037//0012-1649.36.6.767 
Shepard, L. A. (2005). Linking formative assessment to scaffolding. Educational Leadership, 63(3), 66-70.

Siegfried, G. (2011). Goal setting as a motivational technique for neurorehabilitation. In W. M. Cox \& E. Klinger (Eds.) Handbook of motivational counseling: Goalbased approaches to assessment and intervention with addiction and other problems (2nd ed., pp. 571-589). Hoboken, NJ: Wiley-Blackwell.

Sinha, S. P., \& Sharma, A. (2001). Cognitive strategy instruction approach of problem solving for learning disabled children. Journal of Indian Psychology, 19(1-2), 3338.

Slocum, S.K., \& Tiger, J.H. (2011). An assessment of the efficiency of and children preference for forward and backward chaining. Journal of Applied Behavioral Analysis, 44(4), 793-805.

Smith, J. L., Wagaman, J., \& Handley, I. M. (2009). Keeping it dull or making it fun: Task variation as a function of promotion versus prevention focus. Motivation \& Emotion, 33, 150-160. doi: 10.1007/s11031-008-9118-9

Substance Abuse and Mental Health Services Administration. (2002). Report to congress on the prevention and treatment of co-occurring substance abuse disorders and mental disorders. Retrieved from http://www.samhsa.gov/reports/congress2002/chap4icacd.htm

Substance Abuse and Mental Health Services Administration. (2010). Cognitive Behavioral Intervention for Trauma in Schools (CBITS). Retrieved from http://nrepp.samhsa.gov/ViewIntervention.aspx?id=153 
U.S. Department of Education. (2000). Twenty-second annual report to congress on the implementation of the Individuals with Disabilities Education Act. Washington, DC.

U.S. Department of Education. (2001). Twenty-fourth annual report to congress on the implementation of the Individuals with Disabilities Education Act. Washington, DC.

U.S. Department of Education. (2008). Thirtieth annual report to congress on the implementation of the Individuals with Disabilities Education Act, 2008. Washington, DC.

Vitulano, L.A. (2003). Psychosocial issues for children and adolescents with chronic illness: Self-esteem, school functioning and sports participation. Child and Adolescent Psychiatric Clinics of North America, 12, 585-592. doi:

$10.1016 / \mathrm{S} 1056-4993(03) 00027-0$

Wagner, M., \& Cameto, R. (2004). The characteristics, experiences, and outcomes of youth with emotional disturbances. NLTS2 Data Brief, 3(2).

Ward, A., \& Rodger, S. (2004). The application of Cognitive Orientation to daily Occupational Performance (CO-OP) with children 5-7 years with developmental coordination disorder. British Journal of Occupational Therapy, 67(6), 256-264.

Watling, R., \& Schwartz, I. S. (2004). Understanding and implementing positive reinforcement as an intervention strategy for children with disabilities. American Journal of Occupational Therapy, 58, 113-116.

Wells, A.M., Chasnoff, I.J., Schmidt, C.A., Telford, E., \& Schwartz L. D. (2012). Neurocognitive habilitation therapy for children with fetal alcohol spectrum 
disorders: An adaptation of the Alert Program. American Journal of Occupational Therapy, 66(1), 24-34.

Wehmeyer, M. L., Palmer, S. B., Agran, M., Mithaug, D. K., \& Martin, J. E. (2000). Promoting causal agency: The self-determined learning model of instruction. Exceptional Children, 66, 439-453.

Williams, M., \& Shellenberger, S. (1996). How does your engine run? A leader's guide to the Alert Program for Self-regulation. Albuquerque, NM: TherapyWorks.

Winner, M. G. (2000). Inside out: What makes the person with social cognitive deficits tic? San Jose, California: Social Thinking Publishing.

Winner, M. G. (2005). Think social! San Jose, California: Social Thinking Publishing.

Winner, M. G. (2007). Thinking about YOU thinking about ME. San Jose, California: Social Thinking Publishing. 
APPENDIX 
Motivating the Unmotivated Child: Using Psychosocial Intervention Methods in the School

Kristi Fickes, MOTS; Kelsey Hoffmann, MOTS; \& Sarah K. Nielsen, PhD, OTR/L University of North Dakota

Author Note

Kristi Fickes, MOTS, Department of Occupational Therapy, School of Medicine and Health Sciences, University of North Dakota; Kelsey Hoffmann, MOTS, Department of Occupational Therapy, School of Medicine and Health Sciences, University of North Dakota; Sarah K. Nielsen, PhD, OTR/L, Department of Occupational Therapy, School of Medicine and Health Sciences, University of North Dakota.

Correspondence concerning this article should be addressed to Sarah K. Nielsen, Department of Occupational Therapy, School of Medicine and Health Sciences, University of North Dakota, Stop 7126, Grand Forks, North Dakota 58202-7126. E-mail; sarah.k.nielsen@med.und.edu 


\begin{abstract}
School-based occupational therapists have reported barriers to working with children with psychosocial needs including a limited knowledge of psychosocial methods (Barnes, Beck, Vogel, Grice, \& Murphy, 2003; Case-Smith \& Archer, 2008). These issues prevent children with motivational and behavioral issues from receiving the best care possible and, in some cases, from receiving therapy at all. Findings of a literature review suggested that continuing education was correlated with increased confidence in employing psychosocial methods. Eight concepts that occupational therapists can apply to engage the unmotivated child in the therapy process are described and application examples are provided in this article.
\end{abstract}

Keywords: motivating children, mental health, psychosocial intervention, schoolbased occupational therapy 


\section{Introduction}

Case 1: Max is a 12-year-old boy with Asperger's Syndrome receiving occupational therapy. His mother and teacher have voiced concerns about the difficulty Max experiences with developing and maintaining friendships, perseverating on a limited range of topics, displaying social awkwardness, and failing to make eye contact with others. These difficulties are especially evident on the playground, in the lunchroom, in gym class, and in transitioning to and from class. Max talks about reptiles constantly and demonstrates difficulty remaining on task when not discussing this area of interest. He can become easily frustrated with change and lacks skills to cope with situations he finds stressful.

Case 2: Jada is a 7-year-old girl who demonstrates difficulty with motor planning. In occupational therapy, Jada has been working on cutting, gluing, handwriting, and shoe tying. Recently, Jada demonstrated decreased motivation to participate in school and therapy, often stating she is "sad". The therapist has tried to engage her in discussion about why she is feeling this way, though Jada's engagement has not improved.

Max and Jada represent some of the many children who have motivational and behavioral issues and are receiving school-based occupational therapy. Children with physical and emotional disabilities display psychosocial issues and may be less motivated than their typically developing peers (Gutman, McCreedy, \& Heisler, 2004; Majnemer, Shevell, Law, Poulin, \& Rosenbaum, 2010; Vitulano, 2003). Children seen in schoolbased occupational therapy can exhibit dysthymia, mania, physical aggression, passive aggression, physical self-injury, emotional self-injury, obsessiveness and rigidity, perseveration, dislike of novel situations, and inadequate social skills (Gutman et al., 
2004). Behaviors displayed by these children include low frustration tolerance, poor selfregulation, and poor self-control (Miller, Reisman, McIntosh, \& Simon, 2001).

Occupational therapists should address motivational and behavioral issues because school performance, the focus of occupational therapy services in the school setting, can be negatively impacted. According to Case-Smith (2005), socially acceptable behavior is related to the student's academic success and his or her ability to thrive in other environments. If these issues remain unaddressed, children can carry problems into adolescence and adulthood, which then can become exacerbated when they are unable to create and maintain social relationships (Gutman et al., 2004). As a consequence, many children may be prematurely discharged from therapy or fail to meet desired outcomes (Koller \& Bertel, 2006; Nielsen, 2011).

Whether a child is referred due to behavioral problems or physical disabilities, it is important that occupational therapists use psychosocial strategies to address each child holistically. The American Occupational Therapy Association (2004) asserts that psychosocial skills are central to every aspect of occupational therapy and the person, no matter the setting. Additionally, occupational therapists are one of the few professions on the school team whose education equips them in mental health promotion, prevention, and intervention (AOTA, 2010).

Occupational therapists address the psychosocial performance skills of school children; however, they are addressing them much less frequently than other performance skill areas. School-based therapists also report feeling ill-equipped to use psychosocial strategies in practice (Barnes, Beck, Volgel, Grice \& Murphy, 2003; Beck, Barnes, Vogel, \& Grice, 2006; Case-Smith \& Archer, 2008; Gutman et al., 2004; McDuff, 
Schultz, Andersson, \& Pemberton, 2009). Multiple studies have indicated a need for continuing education on psychosocial strategies (Beck et al., 2006; McDuff et al., 2009; Nielsen, 2011). In fact, school-based therapists' confidence has been found to correlate with the ability to reference continuing education opportunities (Nielsen, 2011). These findings suggest that occupational therapists desire valuable continuing education in order to gain confidence in applying psychosocial strategies and; yet, they are finding it difficult to obtain the education they need.

Described below are eight concepts that occupational therapists can apply when working to engage the unmotivated child in the therapy process. For each of the motivational concepts outlined below, see Table 1.1 and Table 1.2 for applications of the concepts to Max and Jada.

\section{Concepts to Apply to Motivate Children}

\section{Setting and working toward personal goals.}

Goals play an integral role in motivation. Multiple studies have found that when a person is involved in choosing their own goals, they will have increased motivation (Corker \& Donnellan, 2012; Fu, Richards, \& Jones, 2009; Gómez-Miñambres, 2012; Siegfried, 2011) and more success in attaining these goals (Fu, Richards, \& Jones, 2009; Moeller, Theiler, \& Wu, 2011; Siegfried, 2011). By working toward the child's goals, therapists can foster self-determination in their clients which leads to increased motivation. For example, in the Cognitive Orientation to daily Occupational Performance (CO-OP) program, children are assisted in setting goals that are meaningful to them (Polatajko \& Mandich, 2005). Engaging children in this process ensures children find the 
goals to be meaningful, increasing motivation to learn skills, use skills beyond the context of therapy, and generalize learning to other areas.

\section{Fun and variety.}

Anyone who works with children knows that making tasks enjoyable is fundamental to increasing their motivation. Those with low achievement, low motivation to perform for the sake of achievement, tend to be more motivated when the emphasis of the task is on having fun (Hart \& Albarracín, 2009). Variety is also important to motivation and while repetition is important for learning, varying the task can lead to increased motivation (Smith, Wagaman, \& Handley, 2009). Resist the temptation to use the same activities each time a child is seen. Be creative and mix things up.

\section{Problem-solving strategies.}

Often we ask children to complete a task without teaching them the tools or methods that are used to accomplish the task. Conversely, using problem-solving strategies in the process of learning can be motivating to children because it increases their likelihood of success; therefore impacting their self-efficacy (Beckman, 2002). Instead of teaching the content or task, problem-solving strategies teach the student how to approach the content or task they are trying to learn (Beckman, 2002; Rodger, Pham, \& Mitchell, 2009; Sinha \& Sharma, 2001). To use such strategies in practice, complete the following steps: (a) define the strategy, (b) model how to use the strategy, (c) provide sufficient time for guided practice (d) promote self-monitoring of strategy use; and (e) encourage continual use and application to novel situations (Beckman, 2002). 


\section{Experiences of success.}

Experiences of success are important sources of motivation for children. These positive mastery experiences enhance children's self-efficacy (Bandura, 1997). The familiar concept of the "just-right challenge" is essential in intervention. Activities are more enjoyable and motivating to a person when the challenge of the task matches the skill of the person performing it (Cross \& Coster, 1997; Dunkerly, Tickle-Degnen, \& Coster, 1997). Successful experiences can be fostered using a variety of techniques. For example, in the behavioral technique of backwards chaining, a task is taught working backward from the goal to ensure the child experiences the success of completing the task each time they attempt it (Hayward, Gale, \& Eikeseth, 2009).

\section{Feedback.}

Feedback, when given in an appropriate way, can be motivating to children. It is most effective to provide feedback that is formative, helping the student move forward and close the gap between current and desired performance (Shepard, 2005). For example, in scaffolding, the therapist provides support according to the learner's needs to assist the learner in achieving the next steps of her goals (El, Tillema, \& van Koppen, 2012; Shepard, 2005). This support can come in many forms including reminders, hints, and encouragement. However, be careful to provide the least amount of feedback necessary. Ignore small errors that do not impact the process of achieving the short-term goal (Shepard, 2005).

The CO-OP program, which uses guided discovery, provides ideas on how to give feedback appropriately (Polatajko \& Mandich, 2005). In this approach, therapists must be purposeful in their actions and reactions, using principles to help them guide the child. 
Major principles of this approach include: (a) give feedback on one thing at a time; (b) ask rather than tell how a task went; (c) coach, don't adjust; and (d) make it obvious. These principles support the child's own use of strategies to acquire skills and confront future problems (Polatajko \& Mandich, 2005).

\section{Modeling.}

Bandura's Social Learning Theory (1977) proposes that people learn by observing others' behavior and its consequences. People then imitate the behavior that appears to produce desired results. In accordance with this theory, instructors can promote desired behaviors by providing a model for the child to imitate (Margolis \& McCabe, 2006). The model can be an expert who demonstrates how the behavior or task is completed using strategies or skills. When the person models, it is helpful for them to explain what they are thinking and doing at each step (Margolis \& McCabe, 2006). A student is also more likely to believe in their abilities after observing a comparable peer successfully complete an intimidating task (Alderman, 2004). In addition, video modeling, watching a video of a person engaging in a behavior and then practicing that behavior, has been revealed as especially effective with children who have autism (Corbett \& Abdullah, 2005). Each of these forms of modeling has the capacity to enhance children's self-efficacy and motivation (Margolis \& McCabe, 2006).

\section{Feeling in control.}

Research shows that human motivation is sensitive to the amount of control one feels over oneself and the environment (Eitam, Kennedy, \& Tory Higgins, 2013). Providing children with opportunities for self-directed learning enhances selfdetermination, which has important implications for motivation (Wehmeyer, Palmer, 
Agran, Mithaug, \& Martin, 2000). This can include providing choices, giving children responsibilities, fostering self-evaluation, or helping them set their own goals.

Another way children feel in control is through self-regulation. This is the ability to adaptively monitor and control oneself. It encompasses the self-control of emotions, behaviors, and cognitions (Bronson, 2002; Ning \& Downing, 2010). Self-regulation has been associated with adaptive behaviors, such as positive work habits and engagement in learning (Rimm-Kaufman, Curby, Grimm, Nathanson, \& Brock, 2009), and with emerging literacy, vocabulary, and math skills (McClelland, Cameron, Connor, Farris, Jewkes, \& Morrison, 2007). It has also been correlated with positive social outcomes, such as adaptability and social skills (Aro, Eklund, Nurmi, \& Poikkeus, 2012), and with the ability to control one's impulses and delay gratification (Sethi, Mischel, Aber, Shoda, \& Rodriguez, 2000).

Empowering students by teaching self-regulation strategies has been found to increase motivation and improves attitude toward academic success (Ning \& Downing, 2010). Techniques are available to facilitate the development of self-regulation, such as by helping children identify their emotions and cognitions to regulate their behavior. Two programs developed by occupational therapists to facilitate the development of selfregulation are the Alert Program $®($ Williams \& Shellenberger, 1996) and Zones of Regulation $®$ (Kuypers, 2011).

\section{Positive reinforcement.}

Positive reinforcement is the concept of presenting a positive stimulus following a desired behavior to increase the likelihood that a behavior will be repeated (Cole \& Tufano, 2008). This stimulus can be as simple as attention or praise or it can be more 
elaborate, such as the opportunity to engage in a desired activity or earn a party for consistent hard work. While praise is a simple way of increasing motivation, it is not as straightforward as it might seem. For example, according to Cimpian, Acre, Markman, and Dweck (2007), the subtleties of praise make a difference. Their research demonstrates that generic praise, such as telling a child he is a "good drawer," can ultimately have a negative impact on the child's self-concept and motivation. When that child experiences difficulties in the future, mistakes reflect on this ability or trait. Children who had been told they "did a good drawing" were less likely to feel sad or avoid the activity of drawing when mistakes were made and they generated better strategies for fixing their mistakes (Cimpian et al., 2007).

\section{Conclusion}

Many children on occupational therapists' caseloads may demonstrate decreased motivation and withdrawal from the therapy process. This decrease in motivation may occur for many reasons and therapists may feel ill-equipped to deal with the difficult behaviors that occur when the child is unmotivated. Utilizing the strategies discussed in this article can help therapists feel more confident as they re-motivate children to keep them engaged in their course of therapy to ensure academic success. 


\section{References}

Alderman, M. K. (2004). Motivation for achievement: Possibilities for teaching and learning (2nd ed.). Mahwah, NJ: Erlbaum.

American Occupational Therapy Association. (2004). The psychosocial aspects of occupational therapy. American Journal of Occupational Therapy, 58, 669-672.

American Occupational Therapy Association. (2010). Specialized knowledge and skills in mental health. American Journal of Occupational Therapy, 64(Suppl.), S30-S43. doi:10.5014/ajot.2010.64S30-64S43

Aro, T., Eklund, K., Nurmi, J. E., \& Poikkeus, A. M. (2012). Early language and behavioral regulation skills as predictors of social outcomes. Journal of Speech, Language, and Hearing Research, 55, 395-408. doi: 10.1044/1092-4388(2011/100245)

Bandura, A. (1977). Social learning theory. New York: General Learning Press. Bandura, A. (1997). Self-efficacy: The exercise of control. New York: Freeman.

Barnes, K. J., Beck, A. J., Vogel, K. A., Grice, K. O., \& Murphy, D. (2003). Perceptions regarding school-based occupational therapy for children with emotional disturbances. American Journal of Occupational Therapy, 57, 337-341.

Beckman, P. (2002). Strategy instruction. Retrieved from ERIC database. (ED474302)

Beck, A. J., Barnes, K. J., Vogel, K. A., \& Grice, K. O. (2006). The dilemma of psychosocial occupational therapy in public schools: The therapists' perceptions. Occupational Therapy in Mental Health, 22, 1-17.

Bronson, M. B. (2002). Self-regulation in early childhood, nature and nurture. New York, NY: The Guilford Press. 
Case-Smith, J. (2005). Occupational therapy and children. St. Louis, MO: Elsevier Mosby.

Case-Smith, J., \& Archer, L. (2008). School-based services for students with emotional disturbance: Findings and recommendations. OT Practice, 13(1), 17-21.

Cimpian, A., Acre, H. M., Markman, E. M., \& Dweck, C. S. (2007). Subtle linguistic cues affect children's motivation. Psychological Science, 18, 314-316. doi: $10.1111 / \mathrm{j} .1467-9280.2007 .01896 . x$

Corbett, B. A., \& Abdullah, M. (2005). Video modeling: Why does it work for children with autism. Journal of Early and Intensive Behavior Intervention, 2(1), 2-8.

Corker, K. S., \& Donnellan, M. B. (2012). Setting lower limits high: The role of boundary goals in achievement motivation. Journal of Educational Psychology, 104(1), 138-149.

Cole, M. B., \& Tufano, R. (2008). Applied theories in occupational therapy: A practical approach. Thorofare, NJ: Slack Incorporated.

Cross, L.A., \& Coster, W.J. (1997). Symbiotic play language during sensory integration treatment. American Journal of Occupational Therapy, 51 (10), 808-814.

Dunkerly, E., Tickle-Degnen, L., \& Coster, W.J. (1997). Therapist-child interaction in the middle minutes of sensory integration treatment. American Journal of Occupational Therapy, 51 (10), 799-805.

Eitam, B., Kennedy, P. M., \& Tory Higgins, E. (2013). Motivation from control. Experimental Brain Research, Published online. doi: 10.1007/s00221-012-3370-7 
El, R. P., Tillema, H., \& van Koppen, S. (2012). Effects of formative feedback on intrinsic motivation: Examining ethnic differences. Learning and Individual Differences, 22(4), 449-454. doi: 10.1016/j.lindif.2012.04.001

Fu, F. Q., Richards, K. A., \& Jones, E. J. (2009). The motivation hub: Effects of goal setting on self-efficacy on effort and new product sales. Journal of Personal Selling \& Sales Management, 29(3), 277-292.

Gómez-Miñambres, J. (2012). Motivation through goal setting. Journal of Economic Psychology, 33(6), 1223-1239.

Gutman, S.A., McCreedy, P., \& Heisler, P. (2004). The psychosocial deficits of children with regulatory disorders: Identification and treatment. Occupational Therapy in Mental Health, 20(2), 1-32.

Hart, W., \& Albarracin, D., (2009). The effects of chronic achievement motivation and achievement primes on the activation of achievement and fun goals. Journal of Personality and Social Psychology, 97(6), 1129-1141.

Hayward, D.W., Gale, C.M., \& Eikeseth, S. (2009). Intensive behavioural intervention for young children with autism: A research-based service model. Research in Autism Spectrum Disorders, 3(3), 571-580.

Koller, J.R., \& Bertel, J.M. (2006). Responding to today's mental health needs of children, families, and schools: Revisiting the preservice training and preparation of school-based personnel. Education \& Treatment of Children, 29(2), 197-217.

Kuypers, L. (2011). The zones of regulation. San Jose: Social Thinking.

McClelland, M. M., Cameron, C. E., Connor, C. M., Farris, C. L., Jewkes, A. M., \& Morrison, F. J. (2007). Links between behavioral regulation and preschoolers' 
literacy, vocabulary, and math skills. Developmental Psychology, 43(4), 947-959. doi: $10.1037 / 0012-1649.43 .4 .947$

Majnemer, A., Shevell, M., Law, M., Poulin, C., \& Rosenbaum, P. (2010). Level of motivation in mastering challenging tasks in children with cerebral palsy. Developmental Medicine \& Child Neurology, 52(12), 1120-1126. doi: $10.1111 / \mathrm{j} .1469-8749.2010 .03732 . x$

Margolis, H., \& McCabe, P. P. (2006). Improving self-efficacy and motivation: What to do, what to say. Intervention in School and Clinic, 41(4), 218-227.

McDuff, S., Schultz, S., Andersson, E., \& Pemberton, J. (2009). Meeting the psychosocial needs of the students in special education: An ethnographic study. Journal of Occupational Therapy, Schools, \& Early Intervention, 2, 205-216.

Miller, L., Reisman, J., McIntosh, D., \& Simon, J. (2001). An ecological model of sensory modulation. In S. Smith Roley, E. Blanche, \& R. Schaaf (Eds.), Understanding the nature of sensory integration with diverse populations (pp. 57-82). San Antonio, TX: Therapy Skill Builders.

Moeller, A.J., Theiler, J.M., \& Wu, C. (2011). Goal setting and student achievement: A longitudinal study. The Modern Language Journal, 96(ii), 153-169. doi: $10.1111 / \mathrm{j} .1540-4781.2011 .01231 . x$

Nielsen, S.K. (2011). A mixed-methods study examining the effectiveness of psychosocial occupational therapy preparation for therapists working with children in schools. (Unpublished doctoral dissertation). North Dakota State University, Fargo, ND. 
Ning, H. K., \& Downing, K. (2010). The reciprocal relationship between motivation and self-regulation: A longitudinal study on academic performance. Learning and Individual Differences, 20, 682-686. doi: 10.1016/j.lindif.2010.09.010

Polatajko, H. J., \& Mandich, A. D. (2005). Cognitive orientation to daily occupational performance with children with developmental coordination disorder. In N. Katz (Ed.), Cognition \& occupation across the life span (pp. 237-259). Bathesda, MD: AOTA Press.

Rimm-Kaufman, S. E., Curby, T. W., Grimm, K. J., Nathanson, L., \& Brock, L. L. (2009). The contribution of children's self-regulation and classroom quality to children's adaptive behaviors in the kindergarten classroom. Developmental Psychology, 45(4), 958-972. doi: 10.1037/a0015861

Rodger, S., Pham, C., \& Mitchell, S. (2009). Cognitive strategy use by children with Asperger's syndrome during intervention for motor-based goals. Australian Occupational Therapy Journal, 56, 103-111. doi: 10.1111/j.14401630.2007.00719.x

Sethi, A., Mischel, W., Aber, J. L., Shoda, Y., \& Rodriguez, M. L. (2000). The role of strategic attention deployment in development of self-regulation: Predicting preschoolers' delay of gratification from mother-toddler interactions. Developmental Psychology, 36(6), 767-777. doi: 10.1037//0012-1649.36.6.767

Shepard, L. A. (2005). Linking formative assessment to scaffolding. Educational Leadership, 63(3), 66-70.

Siegfried, G. (2011). Goal setting as a motivational technique for neurorehabilitation. In W. M. Cox \& E. Klinger (Eds.) Handbook of motivational counseling: Goal- 
based approaches to assessment and intervention with addiction and other problems (2nd ed.) (pp. 571-589). Hoboken, NJ: Wiley-Blackwell.

Sinha, S. P., \& Sharma, A. (2001). Cognitive strategy instruction approach of problem solving for learning disabled children. Journal of Indian Psychology, 19(1-2), 3338.

Smith, J. L., Wagaman, J., \& Handley, I. M. (2009). Keeping it dull or making it fun: Task variation as a function of promotion versus prevention focus. Motivation \& Emotion, 33, 150-160. doi: 10.1007/s11031-008-9118-9

Vitulano, L.A. (2003). Psychosocial issues for children and adolescents with chronic illness: Self-esteem, school functioning and sports participation. Child and Adolescent Psychiatric Clinics of North America, 12, 585-592. doi: $10.1016 / \mathrm{S} 1056-4993(03) 00027-0$

Wehmeyer, M. L., Palmer, S. B., Agran, M., Mithaug, D. K., \& Martin, J. E. (2000). Promoting causal agency: The self-determined learning model of instruction. Exceptional Children, 66, 439-453.

Williams, M., \& Shellenberger, S. (1996). How does your engine run? A leader's guide to the Alert Program for Self-regulation. Albuquerque, NM: TherapyWorks. 


\begin{tabular}{|c|c|}
\hline Concept & How It Is Applied \\
\hline Modeling & $\begin{array}{l}\text { - As Max's therapist, use yourself as an example. His peers can } \\
\text { also play this role and they can demonstrate the learning } \\
\text { process in addition to the desired behavior. } \\
\text { - Video tape two peers having lunch and review it with Max. }\end{array}$ \\
\hline Feedback & $\begin{array}{l}\text { - Pair Max up with a peer while practicing table manners. Each } \\
\text { child will be responsible for giving feedback to peers based on a } \\
\text { list of criteria. } \\
\text { - Be careful not to make comparative statements regarding the } \\
\text { students. Instead, reference the child's own previous behavior } \\
\text { to note progress. }\end{array}$ \\
\hline Fun and Variety & $\begin{array}{l}\text { - Have Max and his peer group plan a fun recess activity. This } \\
\text { way, Max can have a personal goal to work on appropriate } \\
\text { conversations, but in a fun and exciting way. } \\
\text { - Use a group discussion on reptiles to increase Max's motivation } \\
\text { and work on appropriate interaction with peers. }\end{array}$ \\
\hline $\begin{array}{l}\text { Experience } \\
\text { Success }\end{array}$ & $\begin{array}{l}\text { During a group treatment session, have Max teach the other } \\
\text { students how to do an activity that Max has already mastered. } \\
\text { Prior to the session, work on skills for appropriate social } \\
\text { interaction. These could include going an appropriate speed, } \\
\text { checking if others understand, being patient if they don't, and } \\
\text { keeping good eye contact while speaking. This will make him } \\
\text { feel like an expert on the subject, but will also address his social } \\
\text { goals. }\end{array}$ \\
\hline Feeling in Control & $\begin{array}{l}\text { - Give Max options by making a schedule of activities and letting } \\
\text { Max choose at least one activity to put on the schedule. } \\
\text { Alternate between activities that directly connect to therapy } \\
\text { goals and Max's desired choices or end with Max's desired } \\
\text { activity as a reward for completing the required activities. Give } \\
\text { Max the control to cross finished items off the list and report } \\
\text { what activity is listed next. }\end{array}$ \\
\hline $\begin{array}{l}\text { Positive } \\
\text { Reinforcement }\end{array}$ & $\begin{array}{l}\text { - Max enjoys talking about reptiles and sharing facts. Give Max } \\
\text { time to discuss this topic. One way this could be done is using it } \\
\text { as a reward. For example, tell Max if he completes the desired } \\
\text { activities, he will get the last } 5 \text { minutes to discuss reptiles. } \\
\text { - Give Max verbal praise for a job well done. }\end{array}$ \\
\hline
\end{tabular}




\begin{tabular}{|c|c|}
\hline Concept & How It Is Applied \\
\hline Personal Goals & $\begin{array}{l}\text { After talking with Jada, you find out that her friends like to give } \\
\text { each other notes and cards, but Jada feels embarrassed because } \\
\text { she cannot write as well as they can. Ask her if she would like to } \\
\text { work on writing notes to her friends. During a portion of each } \\
\text { session, Jada spends time practicing her handwriting and } \\
\text { transferring it to notes for her friends. }\end{array}$ \\
\hline Fun and Variety & $\begin{array}{l}\text { - Completing tasks that are fun and different will be more } \\
\text { motivating than completing the same activity. Here are some } \\
\text { examples: } \\
\circ \text { Make thick black silhouettes around pictures of children } \\
\text { and animals in magazines to work on cutting. } \\
\circ \text { Have Jada make a collage for her friend out of magazine } \\
\text { pictures. This will work on cutting and gluing in a way } \\
\text { that is fun and age-appropriate. } \\
\circ \quad \text { Let Jada draw or paint a picture and then make it into a } \\
\text { puzzle. Have her draw in the lines for the puzzle then cut } \\
\text { out the pieces. }\end{array}$ \\
\hline $\begin{array}{l}\text { Problem-Solving } \\
\text { Strategies }\end{array}$ & $\begin{array}{l}\text { - Use the CO-OP program to address fine motor deficits. As part of } \\
\text { her initial therapy sessions, Jada will learn the strategy "Goal- } \\
\text { Plan-Do-Check" (Missiuna, Mandich, Polatajko, \& Malloy-Miller, } \\
\text { 2001). As the name implies, Jada creates a goal, makes a plan to } \\
\text { achieve the goal, carries out the plan, and checks her performance. } \\
\text { - Teach her to apply this strategy to any activity she finds difficult to } \\
\text { perform by having her verbalize each step. By doing this, she is } \\
\text { better able to carry out the activity and it will be easier to assess } \\
\text { where she may be experiencing difficulty (i.e., in creating the plan } \\
\text { or in carrying out the action). }\end{array}$ \\
\hline $\begin{array}{l}\text { Experiences of } \\
\text { Success }\end{array}$ & $\begin{array}{l}\text { - Use backwards chaining to help Jada learn to tie her shoes. } \\
\text { o First, help Jada to master the step of pulling the loop through } \\
\text { the hole and tightening (i.e., the last step of the task). } \\
\text { o Then teach Jada the second-to-last part of the task and so on. In } \\
\text { doing this, Jada always ends the task with an experience of } \\
\text { success (i.e., a fully tied shoe) rather than working to the point } \\
\text { of frustration and giving up. This helps increase her motivation } \\
\text { to continue learning to tie her own shoes. }\end{array}$ \\
\hline
\end{tabular}

